\title{
Optimization of the Supply Chain in the Production of Ethanol from Agricultural Biomass Using Mixed-Integer Linear Programming (MILP): A Case Study
}

\author{
Edgar León-Olivares, ${ }^{1}$ Hertwin Minor-Popocatl $\mathbb{D}^{2},{ }^{2}$ Omar Aguilar-Mejía, ${ }^{2}$ \\ and Diana Sánchez-Partida ${ }^{2}$ \\ ${ }^{1}$ Postgraduate Department, Polytechnic University of Tulancingo, Ingenierías No. 100, Tulancingo de Bravo, HGO, Mexico \\ ${ }^{2}$ School Engineering and Business (Postgraduate), UPAEP University, Puebla, PUE, Mexico \\ Correspondence should be addressed to Hertwin Minor-Popocatl; hertwin.minor@upaep.mx
}

Received 12 August 2019; Revised 14 January 2020; Accepted 30 January 2020; Published 11 March 2020

Academic Editor: Sang-Bing Tsai

Copyright (C) 2020 Edgar León-Olivares et al. This is an open access article distributed under the Creative Commons Attribution License, which permits unrestricted use, distribution, and reproduction in any medium, provided the original work is properly cited.

\begin{abstract}
The production of biofuels from agricultural biomass has attracted much attention from researchers in recent years. Biomass residues generated from agricultural production of corn and barley represent an essential source of raw material for the production of biofuels, and a mathematical programming-based approach can be used to establish an efficient supply chain. This paper proposes a model of mixed-integer linear programming (MILP) that seeks to minimize the total cost of the bioethanol supply chain. The proposal allows determining the optimal number and location of storage centers, biorefineries, and mixing plants, as well as the flow of biomass and bioethanol between the facilities. To show the proposed approach, we present a case study developed in the region of Tulancingo, Hidalgo, in Mexico (case study), considering the potential of biomass (corn and barley residues) in the region. The results show the costs for the production of bioethanol, transportation, and refining and total cost of the bioethanol supply chain, besides a sensitivity analysis on the costs of the bioethanol supply chain which is presented by mixing different percentages of bioethanol with fossil fuel to satisfy the demand. We conclude that the proposed approach is viable in the process of configuring the supply chain within the proposed study region.
\end{abstract}

\section{Introduction}

Countries around the world have considered and directed policies towards the increase and economic use of biomass to meet their future energy demands in order to meet polluting emissions reduction targets, as specified in the Kyoto Protocol, to reduce dependence from fossil fuels [1].

Due to the energy crisis, environmental, and social problems, many researchers have focused on the development of renewable energy (RE) sources to guarantee energy consumption, protect the environment, and promote regional development. Biofuel is a type of RE that can be used in multiple ways to replace energy based on fossil fuels. Bioethanol is a type of biofuel that is currently widely used in internal combustion vehicles [2], which, when mixed with fossil fuel, has the objective of oxygenating it, thus achieving complete combustion that allows reducing toxic emissions [3].

Although first-generation bioethanol production has been commercialized worldwide, it is still debatable about the consumption of food and energy used to get the biofuel. Recently, this trend has changed, and now the focus is on the use of lignocellulose and nonfood biomass products to produce biofuel and thus improve food and energy security [4]. Biomass is considered an alternative source of attractive energy to replace fossil fuels [5], if and only if it occurs without negatively affecting the environment [6] because not all agricultural residues should be used for biofuel production $[7,8]$.

There is much research that assesses the feasibility of producing biofuels from various types of biomass [9-13] and 
different conversion techniques [14, 15]. Currently, many research efforts are directed towards the development of efficient conversion technologies and bioethanol supply chain (Bio-Eth SC) systems that use lignocellulosic biomass like raw materials [4]. The components of the biomass include cellulose, hemicelluloses, lignin, extracts, lipids, proteins, simple sugars, starches, water, hydrocarbons, ash, and other compounds [16]. However, not all the waste produced should be used for the production of bioenergy, since the indiscriminate disposal of waste can lead to a decrease in soil quality with adverse impacts [17].

The main logistical activities in a Bio-Eth SC based on corn and barley agricultural residues include sowing, harvesting, collecting in bales for easy storage and transport, the conversion to bioethanol, and transportation of bioethanol between biorefineries and mixing plants, as well as the transportation of biofuel between mixing plants and customers. It is essential to investigate the number and optimal locations for storage facilities, biorefineries, mixing plants, and finding the optimal allocation of raw materials, as well as the estimation of costs, processing, and transportation in order to facilitate the commercialization of biofuel production [18-24].

The use of the mathematical programming (MP) approach to the design of supply chains for the production of biofuels has been widely addressed in the specialized literature. In [25], a mixed-integer linear programming (MILP) model is proposed for a bioenergy supply chain. This approach proposes to minimize the total cost of the supply chain (SC) as well as to define the capacity and location of production facilities, optimal selection of quantities and sources of biomass, modes of transport, and the links that must be established for the transport of biomass and the products that are delivered to the markets. The proposed approach does not consider mixing plants with fossil fuels.

In [26], a stochastic programming model of mixed integers with two steps is presented for the strategic planning of biofuel supply systems based on biological residues, including maize residues, rice straw, wheat straw, waste forestry, and municipal solid waste (wood, paper, and cotton). The model identifies refineries, size, and location of terminals; the results show that bioethanol production can be viable based on such waste; this proposal does not consider barley residues and no mixing plants.

In [27], an integrated model is developed that includes strategic and tactical decisions simultaneously to optimize forest-based biomass supply chains to produce bioenergy and biofuels, the proposal considers the annual and monthly variations in the supply of biomass, the demand for bioenergy/biofuels, and losses during processing, and storage also determines the opening of conversion facilities; this paper is a case study which shows that the capacity of conversion technologies and the amount of biomass processed by the strategic model are not sufficient to meet the monthly demand for bioenergy; this approach does not consider the inclusion of mixing plants within the SC.

An approach that seeks the optimization of biorefinery locations and the associated transport networks for the production of biofuel using corn stover is presented in [28] through an MILP considering the uncertainty. The case study suggests the implementation of the technology to be used, and the solution manages to meet $10 \%$ of the demand; the proposal only considers agricultural corn residues and does not imply storage centers or mixing plants with fossil fuel.

A stochastic proposal that considers multiple periods in the design of the SC of biofuels based on grass, urban waste, corn stover, wheat straw, and rice is presented in [29]. The proposal considers a system of production, distribution, time stages, locations, and capacities of the technical installations and material flows; this proposal does not consider mixing facilities with fossil fuel or barley biomass.

In [24], an integrated mathematical model to determine the best logistics decisions and minimize the total cost of the grass-based bioethanol SC is proposed; the case study demonstrates the economic viability of producing biofuel from biomass on a commercial scale; the model does not consider storage centers or mixing plants. In [30], an MP approach is presented, to optimize strategic decisions (location and type of facilities) and tactics (assignment) in all types of biomass-based SCs; however, for its implementation, a critical point is to identify the quantitative values for the different parameters of the model.

A linear programming (LP) model is addressed to optimize the SC in [31]; this paper is considering the transport from forest biomass collection sites and corn residues to the biorefineries, but it does not consider a set of customers, barley residues, or plants of mixing with fossil fuel.

In [32], it presents a mathematical model that can be used to design the SC and manage the logistics of a biorefinery, the proposed model coordinates design and logistics decisions, and it also determines the number, size, and location of the biorefineries needed to produce biofuels using biomass from corn and forest residues. The model also determines the amount of biomass sent, processed, and inventoried over some time, including mixing plants, storage centers, and a set of customers. However, it does not consider agricultural residues of barley.

In [33], a conceptual design of a lignocellulosic biorefinery and its supply chain for ethanol production in India is proposed; in this proposal, it is not considered as the use of biomass from barley agricultural waste, nor is it considered in the supply chain as the use of mixing plants and not a set of customers. In [34], a comprehensive model for the design and analysis of bioethanol production and supply strategies from lignocellulosic biomass is developed, taking as a case study the island of Jeju, Korea; in this study, the use of plants mixed and a set of customers represented by regions are considered; also, the authors consider the use of barley waste; however, they do not consider corn waste.

In [35], the authors present a review of 72 research articles published between 2006 and 2015 from a sustainability perspective, as well as the inclusion of uncertainty regarding the design and optimization of biorefineries supply chain management. Derived from the analysis of these publications, it is found that the main objective is an economic benefit, and most of these works develop a deterministic MILP model. 
Another work that makes a review of 146 publications between 1997 and 2016 related to the design of the biomass supply chain is that presented by Ghaderi et al. [20], in which they are reviewed, analyzed, and classified according to their modeling approaches, decisions, uncertainties, solution methodologies, sustainability, model characteristics, entities, data, and regions of the case studies. In the majority of the publications reviewed, the main objective is the total minimization of costs and maximizing benefits; the most widely used mathematical programming approach is the MILP and multicriteria decision-making (MCDM). However, despite the diversity of the types of biomass used in each case study, only one of them [36] uses, among other wastes, corn, and barley for bioethanol production in Northern Italy. However, the model focuses on capacity planning and the problems of selecting technology for bioethanol production in the presence of market uncertainty do not consider a set of mixing plants or customers.

The use of bioethanol in gasoline has become a global trend to reduce $\mathrm{CO}_{2}$ emissions to the atmosphere, increasing the octane number of gasoline and reducing dependence on petroleum products, experimentally [37]. The effect of the use of ethanol and gasoline mixtures in the mechanical, energetic, and environmental performance of the vehicles is studied, concluding that there is a reduction in damages to human health, the ecosystem, and natural resources when the vehicles use a mixture of bioethanol and fossil fuel. According to [38], it is assumed that most engines can operate safely with a mixture of gasoline and ethanol E10 (90\% gasoline and $10 \%$ ethanol). However, it can have a variation from E5 to E100.

The use of bioethanol as an additive to fossil fuel has increased in recent years. However, the use of grains in the production of bioethanol is unacceptable, from the ethical point of view, in a world where there is much inequality, and a considerable part of the population goes hungry [39]. Therefore, the use of raw materials lignocellulosic biomass is being studied intensively to develop bioethanol without using grains for human consumption. The residues of corn and barley are an essential alternative to be used in the production of bioethanol.

In the literature review, we observed that the use of the MP approach in the design of SCs for the production of biofuels from agricultural biomasses is widely used. The presented approaches do not show a combination of agricultural residues of corn and barley nor the inclusion of mixing plants except [32] to combine fossil fuel and biofuel and to be able to respond to the demand of biofuels at competitive prices and in the case study proposed by authors, it includes agricultural residues of corn and barley and the inclusion of mixing plants. Thus, commercial software is the tool used to solve the modeling (commercial solver LINGO 17).

On the other hand, government policy within the study region is to promote sustainable development [40]. Explicitly, the region of the case of study will give impetus to the research and development of projects for the generation and use of alternative energy under sustainability criteria. These favor the use of renewable energies with social and environmental responsibility, develop studies of regional nature that determine the most appropriate form for the generation of energy, and favor the rational use of energy resources derived from the productive processes of the primary sector [41].

In this paper, we study the conditions of the area of the case of study for the production of second-generation bioethanol from agricultural residues in the region (corn and barley) with a four-level Bio-Eth SC. An MILP is formulated that supports the design problem of the Bio-Eth SC proposal, due to the number of cultivation sites, available alternatives to the facilities, and interactions between each level of the Bio-Eth SC. It allows choosing the location of the storage facilities, biorefineries, and mixing plants, as well as cultivation sites and biomass quantities.

The objectives of this study are (1) to determine the availability of biomass for bioethanol production in the proposed study area; (2) to determine the feasible Bio-Eth SC design; (3) to establish the total costs of the Bio-Eth SC; (4) to provide information on the production of bioethanol from corn and barley agricultural residues biomass; (5) to determine the viability of the Bio-Eth SC through a sensitivity analysis using different percentages of mixture between bioethanol and fossil biofuel to satisfy the demand.

\section{Description of the Problem}

For the Bio-Eth SC's strategic design along with planning decisions that minimize the total cost, a model is proposed that integrates facilities for the production of bioethanol based on agricultural residues of corn and barley (see Figure 1).

The proposed model considers sites for biomass harvesting, storage facilities, biorefineries, mixing plants, and customer demand. The biomass is transported between the harvest site and storage centers or biorefineries, and the bioethanol is transported from the biorefineries to the mixing plants with fossil fuel and finally from the mixing plants to the customers (gas stations). The design problem determines the location of the facilities (storage centers, biorefineries, and mixing plants), as well as the harvest sites from where the biomass of corn and barley crops will be collected and flow between facilities.

The model considers aspects such as

(i) All possible locations of the cultivation sites, storage centers, biorefineries, mixing plants, and customers

(ii) The possible supply (a type of biomass and quantity per period) of each harvest site

(iii) Cost of sowing, cultivation, and harvesting for each type of biomass

(iv) The distance between all points of the Bio-Eth SC

(v) Cost of transport mode

(vi) Cost of amortization and the annual operation of the facilities

(vii) Possible capacity values of the facilities 


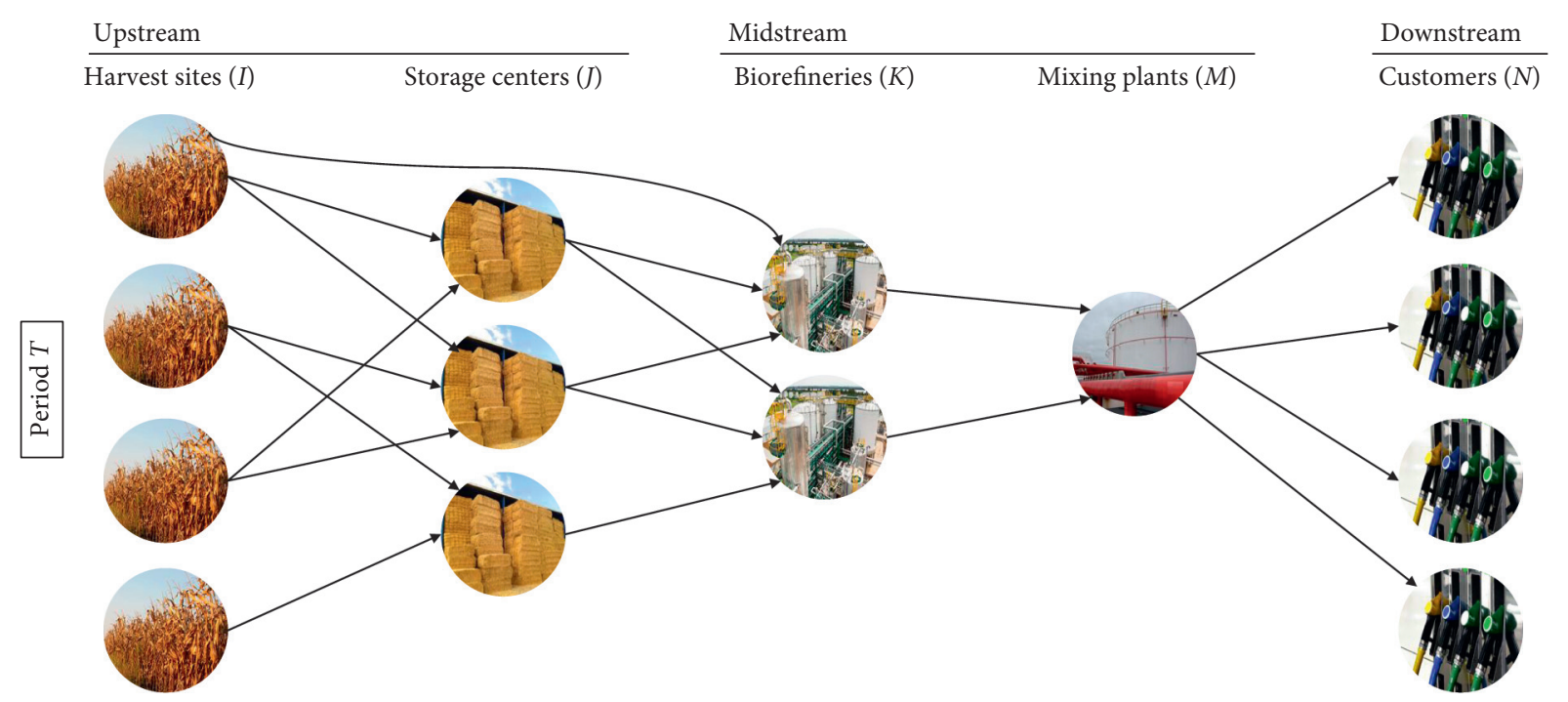

FIgURE 1: Model of the proposed supply chain.

(viii) The conversion factors for each type of biomass in bioethanol

(ix) The demand

To determine

(i) The number and location of harvest sites

(ii) The amount of biomass transported from each harvest site to storage centers and biorefineries

(iii) The amount of bioethanol transported from biorefineries to mixing plants

(iv) Amount of product stored at harvest sites and each facility

(v) Amount of fossil fuel required for mixing with bioethanol

(vi) Amount of biofuel transported to customers

(vii) The number of storage centers, biorefineries, and mixing plants that must be opened

In order to minimize the total cost of the SC and, at the same time, satisfy the established demand, the impact of the yield of corn and barley crops, the loss of dry matter during storage, and the availability of farmland are also considered in the model.

The MILP model proposed in this case study incorporates the following characteristics for the Bio-Eth SC:

(i) For the proposed model, a 75-kilometer zone around the municipality in question covers the states of Hidalgo, Mexico, Puebla, Tlaxcala, and Veracruz and totals 112 municipalities (see Figures 2 and 3)

(ii) Only corn and barley residues are considered

(iii) In this study, two periods are considered: the first is spring-summer that considers harvest of the rainy season and the second is autumn-winter for harvesting in irrigated land
2.1. Assumptions. Then, the different assumptions used in the proposed MILP model are explained.

2.1.1. Location of Storage Centers, Biorefineries, and Mixing Plants. The location of storage centers, biorefineries, and mixing plants have predetermined locations.

2.1.2. Harvesting Method. Harvest costs are only square bales.

2.1.3. The Frequency of the Harvest of Corn and Barley. In the study region, the most important crops are corn and barley; the frequency of collection of agricultural waste derived from barley is done once a year (spring-summer period) and for corn in some places up to twice per year (spring-summer and fall-winter). According to the data obtained from [42-48] in the study region, the planted area is 247,942 and 212,414 ha for maize and barley, respectively. The average biomass yields are $1.95 \mathrm{t} \mathrm{ha}^{-1}$ for corn and $1.99 \mathrm{t}$ $\mathrm{ha}^{-1}$ for barley. Therefore, the biomass potential in the study region is $906,190.76 \mathrm{t}$ of dry matter.

2.1.4. Mode of Transport of Biomass and Bioethanol. In the region of study, the mode of transport is only by road using freight trucks and tankers. The mode of transport directly affects the cost of the logistics chain [2]; in the study region, as the distances to transport the biomass and biofuel do not exceed $300 \mathrm{~km}$, the mode of transport at the lowest cost is by road [49], using cargo trucks and tankers.

2.1.5. Demand. In the present investigation, the demand for biofuel is known for each period; according to the combustible sales data in the study region, it is approximately 988 million litres per year (MLPY) [50]; the demands for each client were determined under a normal distribution, 


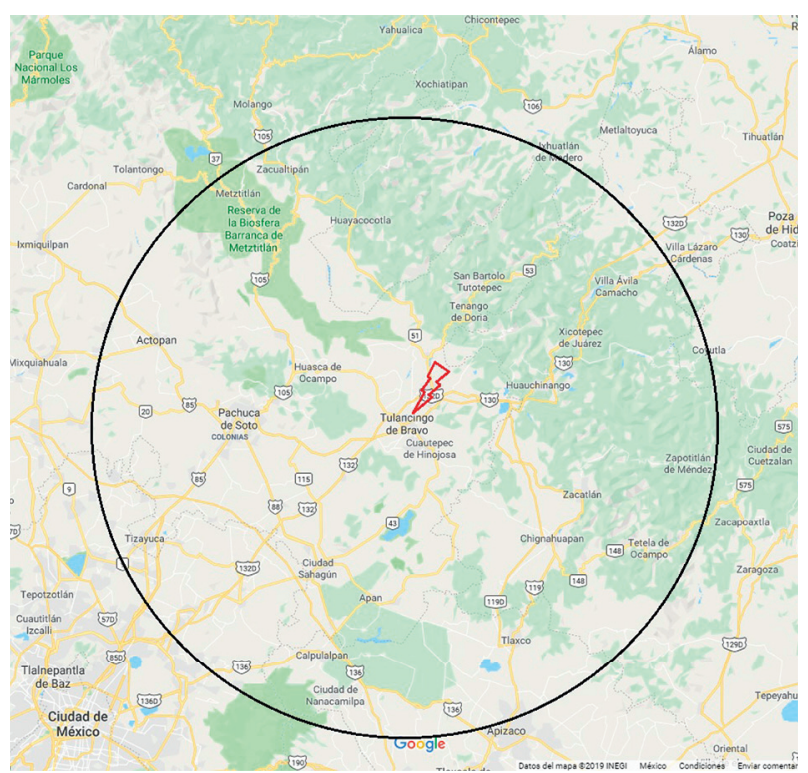

FIGURE 2: Area of influence for the research study. Source: map made using Google Maps.

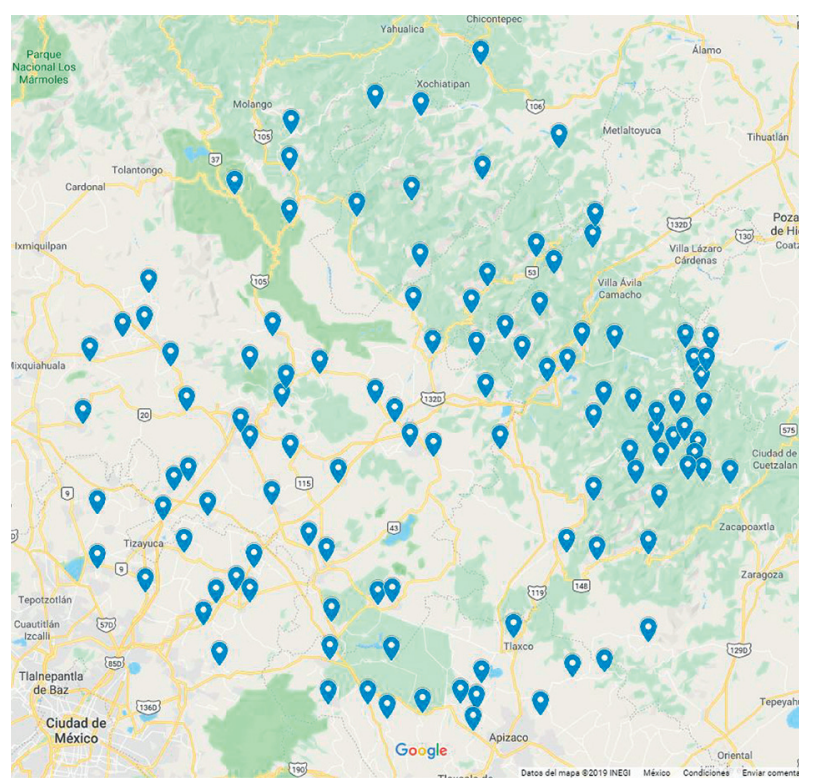

FIGURE 3: Location of harvest sites. Source: map made using Google Maps.

using an average of 4,357,025.76 and standard deviation $1,742,810.30$. Also, each service station is considered like a customer located in the region for the case study.

\section{Mathematical Model}

3.1. Application of MILP. An outstanding approach in the generation and evaluation of a large number of alternatives in the design process of an SC is based on the MILP [36]. Several models have been presented so far to optimize the economic and environmental performance of the SC's biofuel simultaneously. Zhuang and Chang [51] propose a model of mixedinteger programming (MIP) to determine a combination of products for a production process; this study is based on a cost accounting system of time-based activities. Sharifzadeh et al. [52] use an MILP to determine the optimum design and operation of the network of a supply chain under uncertainty, specifically for making systematic and centralized production decisions and distributed and mobile biofuels. Shabani and Sowlati [53] present a nonlinear mixed integer programming approach (MINLP), whose objective is to maximize the value of the supply chain for the generation of electricity from forest biomass, improving profits from the optimal solution; the model developed is a mixed-integer nonlinear programming (MINLP). Lee et al. [34] in their work develop an optimization model using MILP for the design and analysis of bioethanol production and supply strategies from lignocellulosic biomass. Venkat and Shastri [33] develop an MILP model for the conceptual design of a lignocellulosic biorefinery and its supply chain to produce ethanol from agricultural waste in the Indian context.

The proposed approach in this paper is presented as an MILP, considering the framework formulated in this section and using a previously proposed mathematical model [32]. For the problem posed, the indices, parameters, and decision variables are presented in detail, as well as the objective function and restrictions of the model.

\subsection{Models Parameters}

\subsubsection{Sets}

$B$ denotes biomass types

$I$ denotes harvest sites

$J$ denotes storage centers

$K$ denotes biorefineries in a particular location

$M$ denotes mixed plants

$N$ denotes customers

$T$ denotes periods

\subsubsection{Amortization of Facilities}

$\alpha_{j}(\$ /$ year) is the annual cost of construction amortization and operation of the warehouse $j \in J$

$\beta_{k}(\$ /$ year) is the annual amortization of construction and operation of the biorefinery $k \in K$

$\gamma_{m}(\$ /$ year) is the annual amortization of construction and operation of the mixing plant $m \in M$

\subsubsection{Harvest Costs}

$\delta_{i b t}(\$ /$ ha $)$ is the cost of sowing and growing biomass $b \in B$ at the harvest site $i \in I$, in the time $t \in T$

$\eta_{i b t}(\$ /$ ha) is the cost of harvesting the biomass $b \in B$ at the harvest site $i \in I$, in the time $t \in T$

\subsubsection{Holding Costs}

$H_{i b}^{S}(\$ / \mathrm{t})$ is the cost of holding biomass type $b \in B$ per ton at the harvest site $i \in I$ 
$H_{j b}^{W}(\$ / \mathrm{t})$ is the cost of holding biomass type $b \in B$ per ton in the warehouse $j \in J$

$H_{k b}^{B}(\$ / \mathrm{t})$ is the cost of holding biomass type $b \in B$ per ton in the biorefinery $k \in K$

$H_{k}^{E}(\$ / \mathrm{L})$ is the cost of holding bioethanol per litre in the biorefinery $k \in K$

$H_{m}^{M}(\$ / \mathrm{L})$ is the cost of holding biofuel per litre in the mixing plant $m \in M$

\subsubsection{Transport Costs}

$a_{i j}(\$ / \mathrm{t})$ is the cost of transporting a biomass ton from the harvest site $i \in I$ to the warehouse $j \in J$

$b_{i k}(\$ / \mathrm{t})$ is the cost of transporting a biomass ton from the harvest site $i \in I$ to the biorefinery $k \in K$

$c_{j k}(\$ / \mathrm{t})$ is the cost of transporting a biomass ton from the warehouse $j \in J$ to the biorefinery $k \in K$

$d_{k m}(\$ / \mathrm{L})$ is the cost of transporting a bioethanol litre from the biorefinery $k \in K$ to the mixing plant $m \in M$ $e_{m n}(\$ / \mathrm{L})$ is the cost of transporting a biofuel litre from the plant $m \in M$ to the customer $n \in N$.

\subsubsection{Capacities}

$S_{j}^{W}(\mathrm{t})$ is the storage capacity of the warehouse $j \in J$

$S_{k}^{P}(\mathrm{~L})$ is the bioethanol production capacity per year of the biorefinery $k \in K$

$S_{k}^{B}(\mathrm{t})$ is the capacity to store biomass per year of the biorefinery $k \in K$

$S_{m}^{M}(\mathrm{~L})$ is mixing capacity per year of the mixing plant $m \in M$

\subsubsection{The Opening of Facilities}

$n b$ is the maximum number of biorefineries that can be opened

$\mathrm{nm}$ is the maximum number of mixing plants that can be opened

\subsubsection{Other Costs}

$\mu_{t}(\$ / \mathrm{L})$ is the cost per litre of fuel in the period $t \in T$ $\omega_{k b}(\$ / t)$ is the cost of processing a biomass ton, type $b \in B$ in the biorefinery $k \in K$

\subsubsection{Other Parameters}

$L_{i b t}$ is the number of hectares of land at the harvest site $i \in I$ for biomass type $b \in B$, in the time $t \in T$

$P_{i b t}$ is the proportion of land available at the harvest site $i \in I$ with biomass type $b \in B$, in the time $t \in T$

$R_{i b t}(\mathrm{t} / \mathrm{ha})$ is the yield of biomass type $b \in B$ at the harvest site $i \in I$ in the time $t \in T$

$\theta(\%)$ is the percentage of deterioration of stored biomass
$\lambda_{b}(\mathrm{~L} / t)$ is the conversion ratio of biomass type $b \in B$ $D_{n t}(\mathrm{~L})$ is the customer's fuel demand $n \in N$ in the period $t \in T$

$\psi$ is the percentage in which the mixture of bioethanol with fossil fuel is required

$\rho$ is the percentage destined to store biomass in biorefinery $k \in K$

\subsection{Decision Variables}

\subsubsection{Binary Decision Variables}

$X_{j}^{W}$ is a binary variable equal to 1 , if the warehouse $j \in J$ is open, 0 otherwise

$X_{k}^{P}$ is a binary variable equal to 1 , if the biorefinery $k \in K$ is open, 0 otherwise

$X_{m}^{M}$ is a binary variable equal to 1 , if the mixing plant $m \in M$ is open, 0 otherwise

\subsubsection{Decision Variables for Holding}

$Z_{i b t}^{S}$ is the amount of biomass type $b \in B$ stored on the site $i \in I$ in the time $t \in T$

$Z_{j b t}^{W}$ is the amount of biomass type $b \in B$ stored on the warehouse $j \in J$ in the time $t \in T$

$Z_{k b t}^{B}$ is the amount of biomass type $b \in B$ stored in the biorefinery $k \in K$ in the time $t \in T$

$Z_{k t}^{E}$ is the amount of bioethanol stored in the biorefinery $k \in K$ in the time $t \in T$

$Z_{m t}^{M}$ is the amount of biofuel stored in the mixing plant $m \in M$ in the time $t \in T$

\subsubsection{Decision Variables for Sent Quantities}

$Y_{i j b t}^{S}$ is the amount of biomass type $b \in B$ sent from the site $i \in I$ to the warehouse $j \in J$ in the time $t \in T$

$Y_{i k b t}^{W}$ is the amount of biomass type $b \in B$ sent from the site $i \in I$ to biorefinery $k \in K$ in the time $t \in T$

$Y_{j k b t}^{B}$ is the amount of biomass type $b \in B$ sent from the site $j \in J$ to biorefinery $k \in K$ in the time $t \in T$ $Y_{k m t}^{E}$ is the amount of bioethanol sent from biorefinery $k \in K$ to the mixing plant $m \in M$ in the time $t \in T$ $Y_{m n t}^{M}$ is the amount of biofuel sent from the mixing plant $m \in M$ to the customer $n \in N$ in the time $t \in T$

\subsubsection{Other Decision Variables}

$Y_{m t}^{R P}$ is the amount of fossil fuel required in the mixing plant $m \in M$ in the time $t \in T$

$W_{k b t}$ is the amount of biomass type $b \in B$ processed in the biorefinery $k \in K$ in the time $t \in T$

$\phi_{i b t}$ is the amount of biomass type $b \in B$ produced on the harvest site $i \in I$ in the time $t \in T$ 
3.4. Objectives and Objective Function. In the harvest sites $(I)$, the agricultural biomass of corn and barley is generated, and square bales do the collection method. These are sent to the storage centers $(J)$ or directly to the biorefineries $(K)$ in each period $T$. Once the conversion process is completed, the bioethanol is sent from the biorefineries to the mixing plants $(M)$, where it will be combined with fossil fuel to be sent to the customers $(N)$ finally.

In order to minimize the costs of the SC in the MILP model, the decisions that are optimized are the (1) selection of sites of harvest sites $(i) ;(2)$ selection of storage centers $(j)$, which have a predetermined location; (3) selection of biorefineries $(k)$, which have a predetermined location and capacity; (4) flow of biomass material to storage centers and biorefineries; (5) volume of bioethanol during period $(t) ;(6)$ flow of bioethanol to mixing plants $(m)$; $(6)$ flow of biofuel from mixing plants to customers $(n)$ during period $(t)$.

The objective of the proposed model is minimizing the total annual cost of Bio-Eth SC. The cost of the Bio-Eth SC includes the cost of annual amortization of the number of distribution centers, biorefineries, and mixing plants that will be opened, cost of storage of bioethanol in biorefineries and mixing plants, and the cost of storage of biomass in distribution centers and biorefineries. In the same way, the cost of transporting biomass from the harvest sites to distribution centers and biorefineries and from distribution centers to biorefineries is modeled, as is the cost of transporting bioethanol from biorefineries to mixing plants, the cost of transporting biofuel from mixing plants to customers, and the cost of transporting fossil fuel to the mixing plant. Finally, the cost of processing per unit of biomass and cost of sowing, cultivation, and harvesting for the production of biomass are taken into account. The different components of the objective function are explained as follows.

The annual amortization cost of the distribution centers can be defined as

$$
\sum_{j=1}^{J} \alpha_{j} X_{j}^{W}
$$

The cost of annual amortization of biorefineries is

$$
\sum_{k=1}^{K} \beta_{k} X_{k}^{P}
$$

The annual amortization cost of the mixing plants that are opened is defined as

$$
\sum_{m=1}^{M} \gamma_{m} X_{m}^{M}
$$

The cost of storing bioethanol in biorefineries is calculated as

$$
\sum_{t=1}^{T} \sum_{k=1}^{K} H_{k}^{E} Z_{k t}^{E}
$$

The cost of holding bioethanol in the mixing plant is

$$
\sum_{t=1}^{T} \sum_{m=1}^{M} H_{m}^{M} Z_{m t}^{M} .
$$

The cost of holding a unit of biomass at the harvest site is expressed as follows:

$$
\sum_{t=1}^{T} \sum_{b=1}^{B} \sum_{i=1}^{I} H_{i b}^{S} Z_{i b t}^{S} .
$$

The cost of holding units in a storage center is defined as

$$
\sum_{t=1}^{T} \sum_{b=1}^{B} \sum_{j=1}^{J} H_{j b}^{W} Z_{j b t}^{W} .
$$

The cost of maintaining units in biorefinery $k$ of biomass type $b$ can be computed as

$$
\sum_{t=1}^{T} \sum_{b=1}^{B} \sum_{k=1}^{K} H_{k b}^{B} Z_{k b t}^{B} .
$$

The cost of transporting biomass from the harvest site $i$ to the storage center $j$ is

$$
\sum_{t=1}^{T} \sum_{b=1}^{B} \sum_{i=1}^{I} \sum_{j=1}^{J} a_{i j} Y_{i j b t}^{S} .
$$

The cost of transporting biomass from the harvest site $i$ to the biorefinery $k$ is described by

$$
\sum_{t=1}^{T} \sum_{b=1}^{B} \sum_{i=1}^{I} \sum_{k=1}^{K} b_{i k} Y_{i k b t}^{W} .
$$

The cost of transporting biomass from a storage center to the biorefinery is derived as

$$
\sum_{t=1}^{T} \sum_{b=1}^{B} \sum_{j=1}^{J} \sum_{k=1}^{K} c_{j k} Y_{j k b t}^{B} .
$$

Calculating the cost of transporting bioethanol from biorefinery to the mixing plant is given by the relation

$$
\sum_{t=1}^{T} \sum_{k=1}^{K} \sum_{m=1}^{M} d_{k m} Y_{k m t}^{E}
$$

The cost of transporting biofuel from the mixing plant to the $n$ customers is shown in

$$
\sum_{t=1}^{T} \sum_{m=1}^{M} \sum_{n=1}^{N} e_{m n} Y_{m n t}^{M}
$$

The cost of fossil fuel delivered to the mixing plant is determined as

$$
\sum_{t=1}^{T} \sum_{m=1}^{M} \mu_{t} Y_{m t}^{R P} .
$$

The cost of processing biomass to generate bioethanol is computed as

$$
\sum_{t=1}^{T} \sum_{k=1}^{K} \sum_{b=1}^{B} \omega_{k b} W_{k b t}
$$

Growing and harvesting biomass at each harvest site are calculated to determine the costs of sowing: 


$$
\sum_{t=1}^{T} \sum_{i=1}^{I} \sum_{b=1}^{B}\left(\delta_{i b t}+\eta_{i b t}\right) \phi_{i b t}
$$

The fitness function $O$ to be minimized is the next and considers all the above cost elements:

$$
\begin{aligned}
& \min \Omega=\sum_{j=1}^{J} \alpha_{j} X_{j}^{W}+\sum_{k=1}^{K} \beta_{k} X_{k}^{P}+\sum_{m=1}^{M} \gamma_{j} X_{m}^{M}+\sum_{t=1}^{T} \sum_{k=1}^{K} H_{k}^{E} Z_{k t}^{E}+\sum_{t=1}^{T} \sum_{m=1}^{M} H_{m}^{M} Z_{m t}^{M}+\sum_{t=1}^{T} \sum_{b=1}^{B} \sum_{i=1}^{I} H_{i b}^{S} Z_{i b t}^{S} \\
& +\sum_{t=1}^{T} \sum_{b=1}^{B} \sum_{j=1}^{J} H_{j b}^{S} Z_{j b t}^{S}+\sum_{t=1}^{T} \sum_{b=1}^{B} \sum_{k=1}^{K} H_{k b}^{S} Z_{k b t}^{S}+\sum_{t=1}^{T} \sum_{b=1}^{B} \sum_{i=1}^{I} \sum_{j=1}^{J} a_{i j} Y_{i j b t}^{S}+\sum_{t=1}^{T} \sum_{b=1}^{B} \sum_{i=1}^{I} \sum_{k=1}^{K} b_{i k} Y_{i k b t}^{W}+\sum_{t=1}^{T} \sum_{b=1}^{B} \sum_{j=1}^{J} \sum_{k=1}^{K} c_{j k} Y_{k k b t}^{B} \\
& +\sum_{t=1}^{T} \sum_{k=1}^{K} \sum_{m=1}^{M} d_{k m} Y_{k m t}^{E}+\sum_{t=1}^{T} \sum_{m=1}^{M} \sum_{n=1}^{N} e_{m n} Y_{m n t}^{M}+\sum_{t=1}^{T} \sum_{m=1}^{M} \mu_{t} Y_{m t}^{R P}+\sum_{t=1}^{T} \sum_{k=1}^{K} \sum_{b=1}^{B} \omega_{k m} W_{k b t}+\sum_{t=1}^{T} \sum_{i=1}^{I} \sum_{b=1}^{B}\left(\delta_{i b t}+\eta_{i b t}\right) \phi_{i b t} . \\
& \sum_{b=1}^{B} \lambda_{b} W_{k b t}+Z_{k, t-1}^{E}=\sum_{m=1}^{M} Y_{k m t}^{E}+Z_{k t}^{E}, \quad \forall k \in K, t \in T
\end{aligned}
$$
on the number of hectares of biomass collected and the yield of production:

$$
\phi_{i b t} \leq R_{i b t} P_{i b t} L_{i b t}, \quad \forall i \in I, b \in B, t \in T .
$$

Equation (19) guarantees that the shipment of type $b$ biomass from harvest site $i$ to storage center $j$ and biorefinery $k$ at time $t$ is equal to the amount of type $b$ biomass available at harvest site $i$ :

$$
\begin{array}{r}
\sum_{j=1}^{J} Y_{i j b t}^{S}+Z_{i b t}^{S}+\sum_{k=1}^{K} Y_{i k b t}^{W}=\phi_{i b t}+(1-\theta) Z_{i b, t-1}^{S}, \\
\forall i \in I, b \in B, t \in T .
\end{array}
$$

Equation (20) guarantees that the shipment of biomass type $b$ from storage center $j$ to biorefinery $k$ is equal to the amount of type $b$ biomass available in storage center $j$ in each period $t$ :

$$
\begin{aligned}
\sum_{i=1}^{I} Y_{i j b t}^{S}+(1-\theta) Z_{j b, t-1}^{W} & =\sum_{k=1}^{K} Y_{j k b t}^{B}+Z_{j b t}^{W}, \\
& \forall j \in J, b \in B, t \in T .
\end{aligned}
$$

Equation (21) guarantees that the quantity of type $b$ biomass sent from the harvest site $i$ and the storage center $j$ to the biorefinery $k$ is equal to the biomass type $b$ processed in the biorefinery $k$ :

$$
\begin{array}{r}
\sum_{j=1}^{J} Y_{j k b t}^{B}+(1-\theta) Z_{k b, t-1}^{B}+\sum_{i=1}^{I} Y_{i k b t}^{W}=W_{k b t}+Z_{k b t}^{B}, \\
\forall k \in K, b \in B, t \in T .
\end{array}
$$

Equation (22) guarantees that the amount of bioethanol sent from the biorefinery $k$ to the mixing plant $m$ is equal to the amount of bioethanol available in the biorefinery $k$ in the period $t$ :
Equation (23) guarantees that the amount of biofuel sent from the mixing plant $m$ to customers $n$ is equal to the amount of bioethanol available in the mixing plant $m$ in the period $t$ :

$$
\sum_{k=1}^{K} Y_{k m t}^{E}+Z_{m, t-1}^{M}+Y_{m t}^{R P}=\sum_{n=1}^{N} Y_{m n t}^{M}+Z_{m t}^{M}
$$

$\forall m \in M, t \in T$.

Equation (24) guarantees that the amount of biofuel sent from the mixing plants $m$ to the customers $n$ is equal to the demand of each customer $n$, for each period $t$ :

$$
\sum_{m=1}^{M} Y_{m n t}^{M}=D_{n t}, \quad \forall n \in N, t \in T \text {. }
$$

Equation (25) ensures that the quantity of biomass type $b$ sent from harvest sites $i$ to storage centers $j$ does not exceed the capacity of storage centers $j$ :

$$
\sum_{i=1}^{I} \sum_{b=1}^{B} Y_{i j b t}^{S}+\sum_{b=1}^{B} Z_{j b, t-1}^{W} \leq S_{j}^{W} X_{j}^{W}, \quad \forall j \in J, t \in T .
$$

Equation (26) guarantees that the quantity of type $b$ biomass sent from the storage centers $j$ and the harvest sites $i$ to the biorefinery $k$ does not exceed the production capacity of the biorefinery $k$ :

$$
\sum_{j=1}^{J} \sum_{b=1}^{B} Y_{j k b t}^{B}+\sum_{b=1}^{B} Z_{k b, t-1}^{B}+\sum_{i=1}^{I} \sum_{b=1}^{B} Y_{i k b t}^{W} \leq S_{k}^{P} X_{k}^{P}, \quad \forall k \in K, t \in T .
$$

Equation (27) guarantees that the quantity of bioethanol sent from biorefinery $k$, plus the amount of fossil fuel that reaches the mixing plants $m$, does not exceed the mixing capacity of the mixing plant $m$, in period $t$ : 


$$
\sum_{k=1}^{K} Y_{k m t}^{E}+Z_{m, t-1}^{M}+Y_{m t}^{R P} \leq S_{m}^{M} X_{m}^{M}, \quad \forall m \in M, t \in T .
$$

Equation (28) guarantees that the biomass type $b$ in the biorefineries $k$ does not exceed the capacity of the biorefineries $k$ to store biomass for each period $t$ :

$$
\sum_{b=1}^{B} Z_{k b t}^{B} \leq S_{k}^{B}, \quad \forall k \in K, t \in T .
$$

Equation (29) guarantees that the amount of bioethanol stored in the biorefineries $k$ does not exceed the amount of bioethanol produced by the biorefineries $k$, for each period $t$ :

$$
Z_{k t}^{E} \leq S_{k}^{P} \rho, \quad \forall k \in K, t \in T .
$$

Equation (30) guarantees that the quantity of biofuel stored in the mixing plants $m$ does not exceed its mixing capacity, for each period $t$ :

$$
Z_{m}^{M} \leq S_{m}^{M}, \quad \forall m \in M, t \in T .
$$

Equation (31) guarantees that the mixture of bioethanol with fossil fuel is according to the value of $\psi$ :

$$
\left(\sum_{k=1}^{K} Y_{k m t}^{E}+Z_{m, t-1}^{M}\right)\left(\frac{1-\psi}{\psi}\right)=Y_{m t}^{R P}, \quad \forall m \in M, t \in T .
$$

Equation (32) guarantees the opening of at least one storage center $j$ :

$$
\sum_{j=1}^{J} X_{j}^{W} \geq 1
$$

Equation (33) guarantees the opening of the biorefineries $k$ that are indicated in parameter $n b$ :

$$
\sum_{k=1}^{K} X_{k}^{P} \leq n b
$$

Equation (34) guarantees the opening of the mixing plants $m$ that are indicated in the $n m$ parameter:

$$
\sum_{m=1}^{M} X_{m}^{M} \leq n m \text {. }
$$

The following expressions are domain restrictions of decision variables:

$$
\begin{gathered}
Z_{j b t}^{W}, Z_{k t}^{E}, Z_{m}^{M}, Z_{k b t}^{B}, Z_{i b t}^{S} \geq 0, \quad \forall i \in I, j \in J, k \in k, b \in B, m \in M, t \in T, \\
Y_{i j b t}^{S}, Y_{i k b t}^{W}, Y_{j k b t}^{B}, Y_{k m t}^{E}, Y_{m n t}^{M} \geq 0, \quad \forall i \in I, j \in J, k \in k, b \in B, m \in M, n \in N, t \in T, \\
Y_{m t}^{R P}, w_{k b t}, \phi_{i b t} \geq 0, \quad \forall i \in I, \quad k \in k, b \in B, m \in M, n \in N, t \in T, \\
X_{j}^{W}, X_{k}^{P}, X_{m}^{M} \in\{0,1\}, \quad \forall j \in J, k \in K, m \in M .
\end{gathered}
$$

\section{Case of Study}

The analysis of a case study is presented to establish the viability of the proposed approach, which considers biomass of agricultural waste of corn and barley crops in the region of the case of study.

4.1. Input Parameters. The relevant input parameters are as follows:

(1)The modeling horizon is one year, divided into two periods (spring-summer; autumn-winter) $(T=1,2)$

(2)It is considered that the 112 municipalities (see Figure 3 ) that can supply the residues of corn and barley $(i=1, \ldots, 112)$, the cropland data, and the applied yields are in $[42,54]$

(3)Locations for storage centers $(j=1, \ldots, 7)$, biorefineries $(k=1, \ldots, 3)$, and mixing plants $(m=1, . ., 3)$ are predetermined locations to raise the economic activity in these areas (see Figure 4), of which the model should choose the best alternative

(4)The considered capacities for storage centers are 110,000; 200,000; and 300,600 tons and for biorefineries 190 and 380 MLPY [55]. For the mixing plants, the capacities considered are 370 and 555 MLPY; these data are estimated from [56]

(5)There are considered 224 customers ( $n=1, \ldots, 224)$, which represent the same number of gasoline service stations in the study region (see Figure 5)

4.2. Other Parameters. Other input parameters used in the present case are indicated in Tables 1 and 2, and the geographic coordinates of the facilities and harvest sites marked in Figures 3-5 are shown in Table 3.

The MILP model described in Section 3 ((1)-(34)) together with the parameters indicated in this section has 1698 constraints and 7156 variables (13 binary) and was solved with the commercial solver LINGO 17, using a server with an Intel ${ }^{\circledR}$ Xeon ${ }^{\circledR} \mathrm{E} 3-1220 \mathrm{~V} 2 @ 3.10 \mathrm{GHz}$ processor, 8.00 GB in RAM, and Windows 7.0 OS; each value of $\psi$ (mix percentage) was solved with, on average, 2091 iterations in a time of three seconds.

\section{Results}

For the analysis of the proposal, three scenarios are presented considering different percentages of land availability 


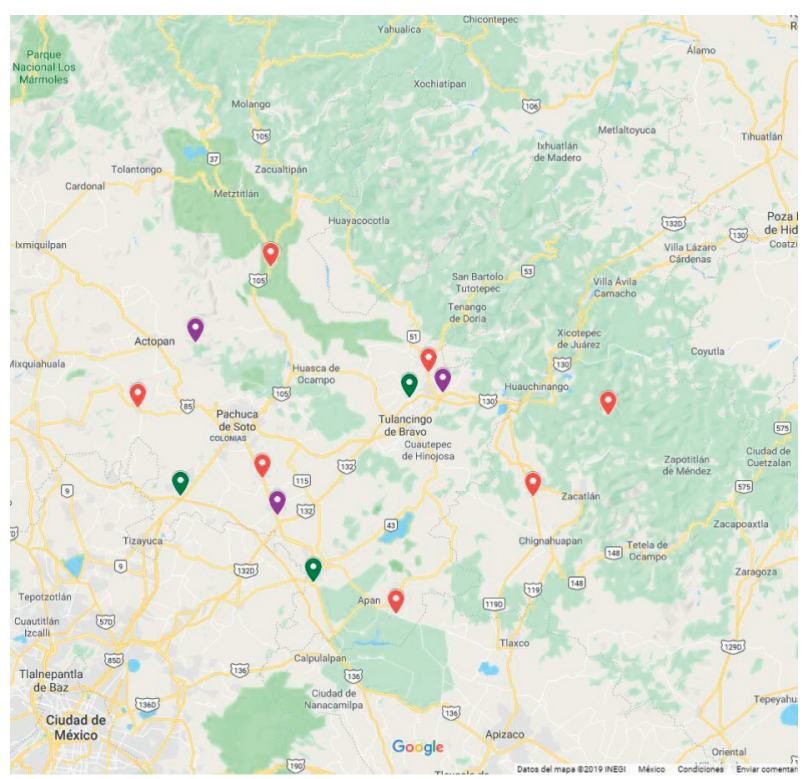

FIGURE 4: Location of storage centers (red), biorefineries (green), and mixing plants (purple). Source: map made using Google Maps.

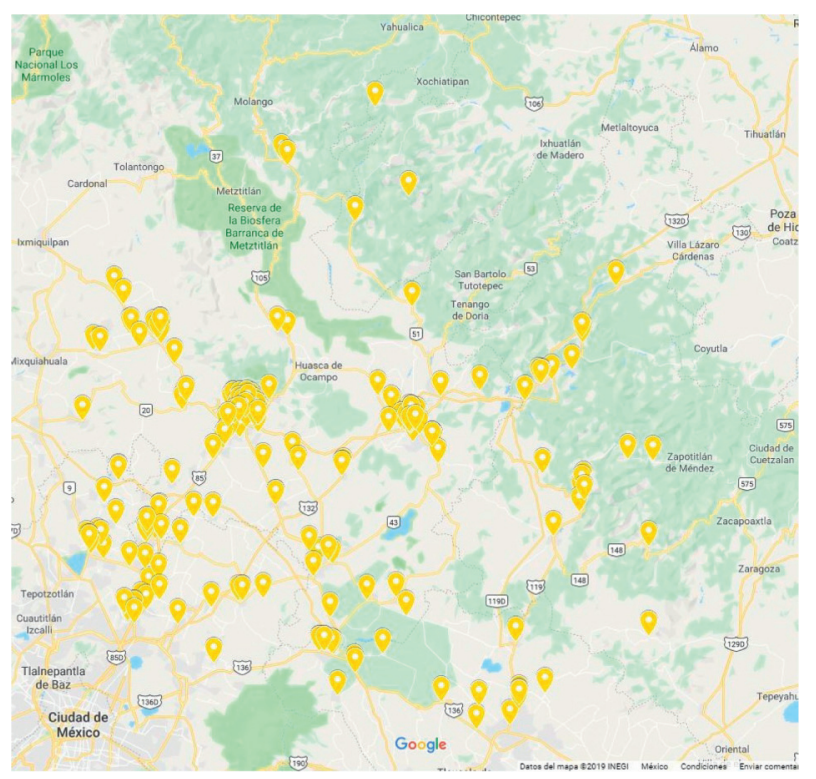

Figure 5: Customer location (gasoline service stations). Source: map made using Google Maps.

at harvest sites (LA1 land availability of 100\%, LA2 land availability $95 \%$, and LA3 land availability $90 \%$ ), as well as different proportions of bioethanol and gasoline mixture in each scenario to evaluate which bioethanol use policy is economically adequate for the study region. The ethanol blending policy is that ethanol and gasoline should be mixed according to a certain proportion, such as E5 (5\% ethanol and 95\% gasoline), E8 (8\% ethanol and 92\% gasoline), E11 (11\% ethanol and 89\% gasoline), E14 (14\% ethanol and $86 \%$ gasoline), E17 (17\% ethanol and 83\% gasoline), and E20 (20\% ethanol and $80 \%$ gasoline). With these three scenarios, we design and analyze the proposed
Bio-Eth SC to identify the optimal configuration and the required costs.

The analysis of cost results for the three scenarios presented is shown in Figure 6. We can see that the best cost is obtained for an E8 mixture in the LA1 scenario; we can also observe that in the LA3 scenario the total cost of the Bio-Eth SC for an E20 mixture is the highest, since, with the total biomass available in the region [54], it would not be possible to meet the demand if only $90 \%$ of the biomass is used, which would imply the importation of biomass from other regions which would significantly increase the cost of transport and therefore the total cost of the supply chain. Figures 7-9 show the amounts of the biomass of each type used in each scenario. Unlike the E20 mix for scenarios LA1 and LA2, in scenario LA3, the amount of biomass used is beyond the maximum amount available.

In scenario LA1 to produce a mixture of E5 and E8, only barley biomass is used (see Figure 7), as in scenarios LA2 and LA3 for a mixture E5 (see Figures 8 and 9), in all other mixtures. It is necessary to use both types of biomass. The strategy to select between corn and barley biomass is obvious. Barley biomass has a better yield in the conversion process than corn biomass; in addition, the harvest sites that produce more barley residues are concentrated around where the biorefinery is selected.

In all scenarios, the number and opening of facilities, as well as the volume of bioethanol produced, are those indicated in Table 4, and only in case of producing an E20 mixture in the three scenarios the opening of two biorefineries would be required, since one is insufficient to produce the amount required to meet demand.

Figures 10-12 show the cost structure of the Bio-Eth SC for the three scenarios. The total cost consists of annual amortization cost for the opening of facilities, biomass harvesting cost, storage cost (biomass and biofuel), transportation cost (biomass and biofuel), gasoline cost, and biomass-processing cost in biorefineries. In the case of the LA3 scenario and a mixture of E20, there is an excess cost due to the shortage of biomass to meet demand. First, it can be seen that the main cost driver of Bio-Eth SC is the cost of supplying liquid fuel due to the huge cost of buying gasoline. As the proportion of ethanol mixture increases, the required amount of gasoline decreases proportionally. Therefore, the purchase cost of gasoline also decreases. However, the high mixing ratio of bioethanol leads directly to the increase in the cost of biomass, transportation, and processing. Because the decrease in the cost of gasoline supply cannot compensate for the increase in the cost of biomass supply, the total cost of the Bio-Eth SC is increased.

The unit cost of mixed biofuel (UCMB) in the three scenarios and for each mixture is calculated by dividing the total cost of the Bio-Eth SC with the total amount of the demand satisfied; the calculated amount varies between 0.99 and $\$ 1.08 / \mathrm{L}$. It is noted that the unit cost of gasoline is obtained according to [59].

In all scenarios, the biomass supply cost and processing cost are the largest contributors to the total cost of the BioEth SC except for the cost of gasoline. 
TABLE 1: Input parameters, $R_{i b t}$, and $H_{i b t}$ ( $b=1$ corn biomass and $b=2$ barley biomass).

\begin{tabular}{|c|c|c|c|c|c|c|c|c|c|c|c|c|c|}
\hline \multirow[t]{3}{*}{ Site $(\mathbf{i})$} & \multirow[t]{3}{*}{ Municipality } & \multicolumn{4}{|c|}{$\begin{array}{l}\text { Grain yield }(t / h) \text { from } \\
\text { site } i \text { for product } b \text {, for } \\
\qquad t=1,2\end{array}$} & \multicolumn{4}{|c|}{$\begin{array}{l}\text { Yields of biomass }(t / h) \\
\text { from site } i \text { for product } \\
\qquad b \text {, for } t=1,2\end{array}$} & \multicolumn{4}{|c|}{$\begin{array}{l}\text { Hectares available for on-site } \\
\text { cultivation } i \text { for product } b \text { at time } \\
\qquad t=1,2\end{array}$} \\
\hline & & $b=1$ & & & $b=2$ & & & & $b=2$ & & $b=2$ & $b=1$ & \\
\hline & & $t=1$ & $t=1$ & $t=2$ & $t=2$ & $t=1$ & & $t=2$ & $t=2$ & $t=1$ & $t=1$ & $t=2$ & $t=2$ \\
\hline 1 & Acatlán, HGO & 1.85 & 2.95 & 0.00 & 0.00 & 1.96 & 2.06 & 0.00 & 0.00 & 8173.00 & 120.00 & 0.00 & 0.00 \\
\hline 2 & Acaxochitlán, HGO & 2.40 & 2.80 & 0.00 & 0.00 & 2.54 & 1.96 & 0.00 & 0.00 & 7306.00 & 115.00 & 0.00 & 0.00 \\
\hline 3 & Actopan, HGO & 74 & 1.00 & 0.00 & 3.80 & 3.96 & 0.70 & 0.00 & 2.66 & 3860.00 & 365.00 & 0.00 & 259.00 \\
\hline 4 & Agua Blanca de Iturbide, HGO & 1.60 & 0.00 & 0.00 & 0.00 & 1.69 & 0.00 & 0.00 & 0.00 & 2801.00 & 0.00 & 0.00 & 0.00 \\
\hline 5 & Ajacuba, HGO & 4.60 & 3.00 & 0.00 & 3.80 & 4.87 & 2.10 & 0.00 & 2.66 & 6270.00 & 544.00 & 0.00 & 119.00 \\
\hline 6 & Almoloya, HGO & 50 & 2.95 & 0.00 & 0.00 & 2.65 & 2.06 & 0.00 & 0.00 & 670.00 & 8953.00 & 0.00 & 0.00 \\
\hline 7 & Apan, HGO & & 1.80 & 0.00 & 0.00 & 2.54 & & 0.00 & 0.00 & & 22856.00 & 0.00 & 0.00 \\
\hline 8 & Atotonilco el Grande, HGO & & 5.20 & 0.00 & 0.00 & 2.10 & 3.64 & 0.00 & 0.00 & 6826.40 & 30 & 0.00 & 0.00 \\
\hline 9 & Cuautepec de Hinojosa, HGO & 10 & 2.00 & 0.00 & 0.00 & 2.22 & 1.40 & 0.00 & 0.00 & 4717.00 & 10790.00 & 0.00 & 0.00 \\
\hline 10 & El Arenal, HGO & 45 & 1.80 & 0.00 & 0.00 & 4.71 & 1.26 & 0.00 & 0.00 & 1940.00 & 45.00 & 0.00 & 0.00 \\
\hline 11 & Emiliano Zapata, HGO & & 2.15 & 0.00 & 0.00 & & & 0.00 & 0.00 & & & & 0.00 \\
\hline 12 & Epazoyucan, HGO & & & 0.00 & 0.00 & & & 0.00 & 0.00 & & & & \\
\hline 13 & Francisco I. Madero, HGO & & 3.00 & 0.00 & 3.80 & 5.75 & 2.10 & 0.00 & 2.66 & 247 & & 0.00 & 100.00 \\
\hline 14 & Huasca de O & 3 & 1.45 & 0.00 & 0.00 & 2.04 & 1.01 & 0.00 & 0.00 & 624 & 85. & 0.00 & 0.00 \\
\hline 15 & uehuetla. HGO & & 0.00 & 0.80 & 0.00 & 1.06 & 0.00 & 0.84 & 0.00 & 0 & 0.00 & 730.00 & 0.00 \\
\hline 16 & Mete & & 1.60 & 0.00 & 0.00 & & & 0.00 & 0.00 & 507 & 2120 & & .00 \\
\hline 17 & Metzt & & 0.00 & 8.00 & 0.00 & 4.31 & 0.00 & 8.48 & 0.00 & 368 & 0.00 & 800.00 & .00 \\
\hline 18 & molo lo Doforme & 0 & 2.25 & 0.00 & 4.00 & 2.96 & 1.57 & 0.00 & 2.80 & 385.00 & & 0.00 & 89.00 \\
\hline 19 & O & 3 & 1.10 & 0.00 & 0.00 & 2.14 & 0.77 & 0.00 & 0.00 & 146 & & 0.00 & 0.00 \\
\hline 20 & Mineral del Monte, HGO & 0.85 & 1.10 & 0.00 & 0.00 & 0.90 & 0.77 & 0.00 & 0.00 & 370.00 & 66. & 0.00 & 0.00 \\
\hline 21 & Omitlán de Juárez, HGO & 1.08 & 1.00 & 0.00 & 0.00 & 1.14 & 0.70 & 0.00 & 0.00 & 1266.00 & & 0.00 & 0.00 \\
\hline 22 & Pachuca de Soto, HGO & 80 & 0.90 & 0.00 & 0.00 & 1.90 & 0.63 & 0.00 & 0.00 & 94.75 & 2760.00 & 0.00 & 0.00 \\
\hline 23 & San Agustín Metzquititlán, HGO & 2.78 & 1.80 & 7.50 & 0.00 & 2.94 & 1.26 & 7.95 & 0.00 & 1800.00 & 10.00 & 68.00 & 0.00 \\
\hline 24 & San Agustín Tl & & 2.00 & & 0.00 & & & 0.00 & & & 396 & & \\
\hline 25 & San B & & & & & & & & & & & & \\
\hline 26 & r, HGO & 18 & 1.10 & 0.00 & 3.50 & 5.48 & 0.77 & 0.00 & 2.45 & 0 & 75 & 0.00 & 55.00 \\
\hline 27 & aya, HGO & 93 & 1.10 & 0.00 & 3.50 & 5.22 & 0.77 & 0.00 & 2.45 & 2650.00 & 105.00 & 0.00 & 32.70 \\
\hline 28 & S & & 2.70 & 0.00 & 0.00 & & 1.89 & 0.00 & 0.00 & 0 & & & 0.00 \\
\hline 29 & & & & & 0.00 & & & & & & & & \\
\hline 30 & GO & 5 & 0.00 & 1.20 & 0.00 & 1.21 & 0.00 & 1.27 & 0.00 & 27 & 0.00 & 800 & .00 \\
\hline 31 & Tepeapulco, HGO & 85 & 2.25 & 0.00 & 0.00 & 3.02 & 1.57 & 0.00 & 0.00 & 761.00 & 7205.00 & 0.00 & 0.00 \\
\hline 32 & , HGO & & 0.00 & 0.95 & 0.00 & 1.27 & 0.00 & 1.00 & 0.00 & 1220 & 0.00 & 511.00 & 0.00 \\
\hline 33 & & & & 0.00 & 0.00 & & & & & & & & \\
\hline 34 & $\mathrm{O}$ & 5 & 2.15 & 0.00 & 0.00 & 1.96 & 1.50 & 0.00 & 0.00 & 21 & & 0.00 & 0.00 \\
\hline 35 & a, HGO & 43 & 0.90 & 0.00 & 0.00 & 2.57 & 0.63 & 0.00 & 0.00 & 106 & 2905.00 & 0.00 & 0.00 \\
\hline 36 & & & 1.80 & 0.00 & 0.00 & 2.65 & 1.26 & 0.00 & 0.00 & 5120 & & & 0.00 \\
\hline 37 & Villa de Tezontepec, HGO & & 1.50 & 0.00 & 0.00 & 3.12 & 1.05 & 0.00 & 0.00 & & 238 & 0.00 & 0.00 \\
\hline 38 & Zacualtipán de Ángeles, HGO & 5 & 1.10 & 1.10 & 0.00 & 1.00 & 0.77 & 1.16 & 0.00 & 0 & 14.00 & 88.00 & 0.00 \\
\hline 39 & Zapotlán de Juárez, HGO & 2.34 & 1.00 & 0.00 & 0.00 & 2.48 & 0.70 & 0.00 & 0.00 & 638.00 & 4357.00 & 0.00 & 0.00 \\
\hline 40 & & & 1.00 & 0.00 & 0.00 & 2.12 & 0.70 & 0.00 & 0.00 & 2309.50 & 13668.00 & 0.00 & 0.00 \\
\hline 41 & MEX & & 1.70 & 0.00 & 0.00 & 2.49 & 1.19 & 0.00 & 0.00 & 1320.00 & & 0.00 & 0.00 \\
\hline 42 & & & 1.70 & 0.00 & 0.00 & & 1.19 & 0.00 & 0.00 & & & & 0.00 \\
\hline 43 & Nopaltepec, MEX & 1.30 & 1.80 & 0.00 & 0.00 & 1.37 & 1.26 & 0.00 & 0.00 & 404.00 & 3381.00 & 0.00 & 0.00 \\
\hline 44 & Otumba, MEX & 2.67 & 2.00 & 0.00 & 0.00 & 2.82 & 1.40 & 0.00 & 0.00 & 990.00 & 4235.00 & 0.00 & 0.00 \\
\hline 45 & n Martín de las Pirámid & 2.63 & 2.25 & 0.00 & 0.00 & 2.78 & 1.57 & 0.00 & 0.00 & & 16.00 & 0.00 & 0.00 \\
\hline 46 & & & 1.30 & 0.00 & 0.00 & & 0.91 & 0.00 & 0.00 & & & & 0.00 \\
\hline 47 & a, MEX & 1.28 & 1.85 & 0.00 & 0.00 & 1.35 & 1.29 & 0.00 & 0.00 & 1452.00 & 10361.00 & 0.00 & 0.00 \\
\hline 48 & Teotihuacán, MEX & 3.27 & 2.18 & 0.00 & 0.00 & 3.46 & 1.52 & 0.00 & 0.00 & 1995.00 & 59.00 & 0.00 & 0.00 \\
\hline 49 & c, MEX & 2.85 & 1.80 & 0.00 & 0.00 & 3.02 & 1.26 & 0.00 & 0.00 & 969.00 & 1303.50 & 0.00 & 0.00 \\
\hline 50 & Zumpango, MEX & 3.80 & 1.70 & 0.00 & 0.00 & 4.02 & 1.19 & 0.00 & 0.00 & 10015.00 & 2382.00 & 0.00 & 0.00 \\
\hline 51 & Ahuacatlán, PUE & 0.85 & 0.00 & 0.00 & 0.00 & 0.90 & 0.00 & 0.00 & 0.00 & 976.00 & 0.00 & 0.00 & 0.00 \\
\hline 52 & Ahuazotepec, PUE & 1.40 & 0.00 & 0.00 & 1.10 & 1.48 & 0.00 & 0.00 & 0.77 & 1240.00 & 0.00 & 0.00 & 169.70 \\
\hline 53 & n, PUE & 0.87 & 0.00 & 1.08 & 0.00 & 0.91 & 0.00 & 1.14 & 0.00 & 372.00 & 0.00 & 223.00 & 0.00 \\
\hline 54 & Aquixtla, PUE & 1.67 & 1.90 & 0.00 & 0.00 & 1.76 & 1.33 & 0.00 & 0.00 & 4336.49 & 20.00 & 9.49 & 0.00 \\
\hline 55 & Camocuautla, PUE & 0.97 & 0.00 & 2.10 & 0.00 & 1.03 & 0.00 & 2.22 & 0.00 & 325.00 & 0.00 & 75.00 & 0.00 \\
\hline 56 & Chiconcuautla, PUE & 1.00 & 0.00 & 1.50 & 0.00 & 1.06 & 0.00 & 1.59 & 0.00 & 857.00 & 0.00 & 149.80 & 0.00 \\
\hline
\end{tabular}


TABle 1: Continued.

\begin{tabular}{|c|c|c|c|c|c|c|c|c|c|c|c|c|c|}
\hline \multirow[t]{3}{*}{ Site $(\mathbf{i})$} & \multirow[t]{3}{*}{ Municipality } & \multicolumn{4}{|c|}{$\begin{array}{l}\text { Grain yield }(t / h) \text { from } \\
\text { site } i \text { for product } b \text {, for } \\
\qquad t=1,2\end{array}$} & \multicolumn{4}{|c|}{$\begin{array}{l}\text { Yields of biomass }(t / h) \\
\text { from site } i \text { for product } \\
\qquad b \text {, for } t=1,2\end{array}$} & \multicolumn{4}{|c|}{$\begin{array}{c}\text { Hectares available for on-site } \\
\text { cultivation } i \text { for product } b \text { at time } \\
\qquad t=1,2\end{array}$} \\
\hline & & $b=1$ & $b=2$ & $b=1$ & $b=2$ & $b=1$ & $b=2$ & $b=1$ & $b=2$ & $b=1$ & $b=2$ & $b=1$ & $b=2$ \\
\hline & & $t=1$ & $t=1$ & $t=2$ & $t=2$ & $t=1$ & $t=1$ & $t=2$ & $t=2$ & $t=1$ & $t=1$ & $t=2$ & $t=2$ \\
\hline 57 & Chignahuapan, PUE & 2.01 & 2.10 & 0.00 & 0.00 & 2.12 & 1.47 & 0.00 & 0.00 & 12865.00 & 6800.00 & 0.00 & 0.00 \\
\hline 58 & Coatepec, PUE & 0.88 & 0.00 & 1.06 & 0.00 & 0.93 & 0.00 & 1.12 & 0.00 & 200.00 & 0.00 & 68.00 & 0.00 \\
\hline 59 & Cuautempan, PUE & 0.84 & 0.00 & 0.00 & 0.00 & 0.88 & 0.00 & 0.00 & 0.00 & 1197.00 & 0.00 & 0.00 & 0.00 \\
\hline 60 & Hermenegildo Galeana, PUE & 1.00 & 0.00 & 1.70 & 0.00 & 1.06 & 0.00 & 1.80 & 0.00 & 360.30 & 0.00 & 80.00 & 0.00 \\
\hline 61 & Honey, PUE & 1.90 & 0.00 & 1.70 & 0.00 & 2.01 & 0.00 & 1.80 & 0.00 & 2981.40 & 0.00 & 535.00 & 0.00 \\
\hline 62 & Huauchinango, PUE & 1.35 & 0.00 & 1.90 & 0.00 & 1.43 & 0.00 & 2.01 & 0.00 & 2136.50 & 0.00 & 213.80 & 0.00 \\
\hline 63 & Hueytlalpan, PUE & 0.70 & 0.00 & 1.15 & 0.00 & 0.74 & 0.00 & 1.21 & 0.00 & 480.00 & 0.00 & 435.00 & 0.00 \\
\hline 64 & Huitzilan de Serdán, PUE & 0.70 & 0.00 & 1.00 & 0.00 & 0.74 & 0.00 & 1.06 & 0.00 & 660.00 & 0.00 & 310.00 & 0.00 \\
\hline 65 & Ixtacamaxtitlán, PUE & 1.97 & 1.70 & 0.00 & 0.00 & 2.09 & 1.19 & 0.00 & 0.00 & 11840.00 & 565.00 & 0.00 & 0.00 \\
\hline 66 & Jalpan, PUE & 1.40 & 0.00 & 1.80 & 0.00 & 1.48 & 0.00 & 1.90 & 0.00 & & 0.00 & 348.00 & 0.00 \\
\hline 67 & Jopala, & 0.90 & 0.00 & 1.80 & 0.00 & 0.95 & 0.00 & 1.90 & 0.00 & 1411.00 & 0.00 & 265.00 & 0.00 \\
\hline 68 & Juan Galindo, PUE & 0.80 & 0.00 & 1.70 & 0.00 & 0.84 & 0.00 & 1.80 & 0.00 & 35.00 & 0.00 & 51.00 & 0.00 \\
\hline 69 & Naupan, PUE & 0.80 & 0.00 & 1.70 & 0.00 & 0.84 & 0.00 & 1.80 & 0.00 & 680.70 & 0.00 & & 0.00 \\
\hline 70 & , PUE & 0.65 & 0.00 & 1.00 & 0.00 & 0.68 & 0.00 & 1.06 & 0.00 & & 0 & & 0.00 \\
\hline 71 & Pahuatlán, PUE & 0.80 & 0.00 & 1.60 & 0.00 & 0.84 & 0.00 & 1.69 & 0.00 & 341.00 & 0.00 & 70.30 & 0.00 \\
\hline 72 & Pantepec, PUE & 1.00 & 0.00 & 1.80 & 0.00 & 1.06 & 0.00 & 1.90 & 0.00 & 1215.00 & 0.00 & 98 & 0.00 \\
\hline 73 & San Felipe Tepatlán, PUE & 0.90 & 0.00 & 1.70 & 0.00 & 0.95 & 0.00 & 1.80 & 0.00 & 258.00 & 0.00 & & 0.00 \\
\hline 74 & Tepango de Rodríguez, PUE & 1.02 & 0.00 & 1.15 & 0.00 & 1.07 & 0.00 & 1.21 & 0.00 & 194.00 & 0.00 & 20.50 & 0.00 \\
\hline 75 & Tepetzintla, PUE & 0.81 & 0.00 & 0.00 & 0.00 & 0.86 & 0.00 & 0.00 & 0.00 & 960.00 & 0.00 & 0.00 & 0.00 \\
\hline 76 & Tetela de Ocampo, PUE & 1.96 & 0.00 & 0.00 & 0.00 & 2.07 & 0.00 & 0.00 & 0.00 & 3288.00 & 0.00 & 0.00 & 0.00 \\
\hline 77 & Tlacuilotepec, PUE & 0.80 & 0.00 & 1.70 & 0.00 & 0.84 & 0.00 & 1.80 & 0.00 & 731.30 & 0.00 & 312.00 & 0.00 \\
\hline 78 & Tlaola, PUE & 0.80 & 0.00 & 1.50 & 0.00 & 0.84 & 0.00 & 1.59 & 0.00 & 767.00 & 0.00 & 380.20 & 0.00 \\
\hline 79 & ya, PUE & 0.90 & 0.00 & 1.80 & 0.00 & 0.95 & 0.00 & 1.90 & 0.00 & & 0.00 & & 0.00 \\
\hline 80 & , PUE & 0.80 & 0.00 & 1.80 & 0.00 & 0.84 & 0.00 & 1.90 & 0.00 & 446.00 & 0.00 & 14 & 0.00 \\
\hline 81 & C, PUE & 0.90 & 0.00 & 1.90 & 0.00 & 0.95 & 0.00 & 2.01 & 0.00 & 108 & 0.00 & 279 & 0.00 \\
\hline 82 & Xoch & 0.71 & 0.00 & 1.40 & 0.00 & 0.75 & 0.00 & 1.48 & 0.00 & 720.00 & 0.00 & 350 & 0.00 \\
\hline 83 & Zacatlán, PUE & 1.55 & 1.80 & 0.00 & 0.00 & 1.63 & 1.26 & 0.00 & 0.00 & 1124 & 0.00 & 0.50 & 0.00 \\
\hline 84 & Zapotitlán de Méndez, PUE & 0.88 & 0.00 & 2.40 & 0.00 & 0.93 & 0.00 & 2.54 & 0.00 & 500.00 & 0.00 & 44.00 & 0.00 \\
\hline 85 & Zihuateutla, PUE & 0.80 & 0.00 & 1.80 & 0.00 & 0.84 & 0.00 & 1.90 & 0.00 & 1106 & & 112.70 & 0.00 \\
\hline 86 & la, PUE & .75 & 0.00 & 1.00 & 0.00 & 0.79 & & & & & & 130 & 0.00 \\
\hline 87 & , TLAX & 2.53 & 2.60 & 0.00 & 0.00 & 2.67 & 1.82 & 0.00 & 0.00 & 2025.00 & 2091.00 & 0.00 & 0.00 \\
\hline 88 & $\mathrm{z}$, TLAX & 2.48 & 2.10 & 0.00 & 0.00 & 2.62 & 1.47 & 0.00 & 0.00 & 530.00 & 1601.00 & 0.00 & 0.00 \\
\hline 89 & Calpulalpan, TLAX & .48 & 2.10 & 0.00 & 0.00 & 2.62 & 1.47 & 0.00 & 0.00 & 133 & 9655.00 & 0.00 & 0.00 \\
\hline 90 & Emiliano Zapata, TLAX & 2.90 & 2.30 & 0.00 & 0.00 & 3.07 & 1.61 & 0.00 & 0.00 & & 30.00 & 0.00 & 0.00 \\
\hline 91 & Españita, TLAX & 2.53 & 2.10 & 0.00 & 0.00 & 2.67 & 1.47 & 0.00 & 0.00 & 666 & 4537.00 & 0.00 & 0.00 \\
\hline 92 & Hueyotlipan, TLAX & 2.45 & 2.40 & 0.00 & 0.00 & 2.59 & 1.68 & 0.00 & 0.00 & 1235.00 & 4989.00 & 0.00 & 0.00 \\
\hline 93 & Lázaro Cárdenas, TLAX & 4.50 & 2.30 & 0.00 & 0.00 & 4.77 & 1.61 & 0.00 & 0.00 & 542.00 & 119.00 & 0.00 & 0.00 \\
\hline 94 & Muñoz de Domingo Arenas, TLAX & 2.76 & 2.50 & 0.00 & 0.00 & 2.92 & 1.75 & & 0.00 & & 1110.00 & 0.00 & 0.00 \\
\hline 95 & Nanacamilpa, TLAX & 2.65 & 2.10 & 0.00 & 0.00 & 2.80 & 1.47 & 0.00 & 0.00 & 590.00 & 5059.00 & 0.00 & 0.00 \\
\hline 96 & San Lucas Tecopilco, TLAX & 2.85 & 3.60 & 0.00 & 0.00 & 3.02 & 2.52 & 0.00 & 0.00 & 1436.00 & 718.00 & 0.00 & 0.00 \\
\hline 97 & Sanctórum, TLAX & 2.65 & 2.10 & 0.00 & 0.00 & 2.80 & 1.47 & 0.00 & 0.00 & 400.00 & 2764.00 & 0.00 & 0.00 \\
\hline 98 & Tetla de la Solidaridad, TLAX & 2.80 & 2.50 & 0.00 & 0.00 & 2.96 & 1.75 & 0.00 & 0.00 & & 6101.00 & 0.00 & 0.00 \\
\hline 99 & Tlaxco, TLAX & 2.58 & 2.20 & 0.00 & 0.00 & 2.72 & 1.54 & 0.00 & 0.00 & 4396.00 & 14264.00 & 0.00 & 0.00 \\
\hline 100 & Xaltocan, TLAX & 2.95 & 3.60 & 0.00 & 0.00 & 3.12 & 2.52 & 0.00 & 0.00 & 3814.00 & 1120.00 & 0.00 & 0.00 \\
\hline 101 & Benito Juárez, VER & 0.75 & 0.00 & 0.90 & 0.00 & 0.79 & 0.00 & 0.95 & 0.00 & 5200.00 & 0.00 & 4450.00 & 0.00 \\
\hline 102 & Coahuitlán, VER & 1.82 & 0.00 & 1.60 & 0.00 & 1.92 & 0.00 & 1.69 & 0.00 & 1100.00 & 0.00 & 1070.00 & 0.00 \\
\hline 103 & Coyutla, VER & 1.79 & 0.00 & 1.80 & 0.00 & 1.89 & 0.00 & 1.90 & 0.00 & 2750.00 & 0.00 & 2650.00 & 0.00 \\
\hline 104 & Filomeno Mata, VER & 1.45 & 0.00 & 1.40 & 0.00 & 1.53 & 0.00 & 1.48 & 0.00 & 350.00 & 0.00 & 330.00 & 0.00 \\
\hline 105 & Huayacocotla, VER & 1.40 & 0.95 & 1.20 & 1.10 & 1.48 & 0.66 & 1.27 & 0.77 & 4200.00 & 255.00 & 80.00 & 88.00 \\
\hline 106 & Ilamatlán, VER & 1.20 & 0.00 & 1.20 & 0.00 & 1.27 & 0.00 & 1.27 & 0.00 & 2200.00 & 0.00 & 900.00 & 0.00 \\
\hline 107 & Ixhuatlán de Madero, VER & 1.44 & 0.00 & 1.20 & 0.00 & 1.52 & 0.00 & 1.27 & 0.00 & 7050.00 & 0.00 & 5950.00 & 0.00 \\
\hline 108 & Mecatlán, VER & 1.45 & 0.00 & 1.40 & 0.00 & 1.53 & 0.00 & 1.48 & 0.00 & 800.00 & 0.00 & 750.00 & 0.00 \\
\hline 109 & Texcatepec, VER & 1.00 & 0.00 & 1.20 & 0.00 & 1.06 & 0.00 & 1.27 & 0.00 & 2200.00 & 0.00 & 700.00 & 0.00 \\
\hline 110 & Tlachichilco, VER & 1.36 & 0.00 & 1.00 & 0.00 & 1.44 & 0.00 & 1.06 & 0.00 & 2720.00 & 0.00 & 1075.00 & 0.00 \\
\hline 111 & Zacualpan, VER & 1.30 & 0.00 & 1.20 & 0.00 & 1.37 & 0.00 & 1.27 & 0.00 & 1000.00 & 0.00 & 215.00 & 0.00 \\
\hline 112 & Zontecomatlán, VER & 1.20 & 0.00 & 1.20 & 0.00 & 1.27 & 0.00 & 1.27 & 0.00 & 4000.00 & 0.00 & 990.00 & 0.00 \\
\hline
\end{tabular}


TABLE 2: Other input parameters.

\begin{tabular}{|c|c|c|}
\hline Source & Entry parameters & Value \\
\hline [55] & $\begin{array}{c}\text { Cost of annual amortization of construction and } \\
\text { operation of storage centers (\$/year) }\end{array}$ & $\alpha_{j}=[281,250 ; 156,250 ; 406,250 ; 156,250 ; 156,250 ; 156,250 ; 156,250]$ \\
\hline [55] & $\begin{array}{c}\text { Amount of annual amortization of construction and } \\
\text { operation of the biorefinery (\$/year) }\end{array}$ & $\beta_{k}=[2,437,500 ; 4,500,000 ; 2,437,500]$ \\
\hline [56] & $\begin{array}{c}\text { Cost of annual amortization of the construction and } \\
\text { operation of the mixing plant (\$/year) }\end{array}$ & $\gamma_{m}=[2,191,304.34 ; 3,286,956.52 ; 2,191,304.34]$ \\
\hline$[54,57]$ & Cost of planting and cultivation of biomass $(\$ / h a)$ & $\begin{aligned} \delta_{i b t}=[238.42,131.57](\text { for all } b, i) \text { and } t & =1 \delta_{i b t}=[288.94,164.47](\text { for all } \\
b, i) \text { and } t & =2\end{aligned}$ \\
\hline$[54,57]$ & Cost of harvested biomass ( $\$ /$ ha $)$ & $\eta_{i b t}=[63.15,31.57]($ for all $b, i)$ and $t=1$ \\
\hline $\begin{array}{l}{[19,58]} \\
{[19,58]} \\
{[19,58]}\end{array}$ & $\begin{array}{l}\text { Cost of holding biomass units at harvest sites }(\$ / t) \\
\text { Cost of holding biomass units in storage centers }(\$ / t) \\
\text { Cost of holding biomass units in biorefineries }(\$ / t)\end{array}$ & $\begin{array}{c}\eta_{i b t}=[78.94,41.05](\text { for all } b, i) \text { and } t=2 \\
S h_{i b}=6.3(\text { for all } b, i) \\
A h_{j b}=4.3(\text { for all } b, j) \\
B h_{k b}=4.3(\text { for all } b, k)\end{array}$ \\
\hline Assumed & $\begin{array}{l}\text { Cost of holding bioethanol units in the biorefinery } \\
\qquad(\$ / \mathrm{L})\end{array}$ & $B H_{k}=0.015($ for all $k)$ \\
\hline Assumed & $\begin{array}{l}\text { Cost of holding units of bioethanol in mixing plants } \\
\qquad(\$ / L)\end{array}$ & $M h_{m}=0.015($ for all $m)$ \\
\hline [55] & $\begin{array}{c}\text { Cost of transporting a biomass unit from the harvest } \\
\text { site to storage centers }(\$ / t)\end{array}$ & $a_{i j}=3.85+0.085 *$ distance $_{i j}($ for all $i, j)$ \\
\hline [55] & $\begin{array}{c}\text { Cost of transporting a biomass unit from the harvest } \\
\text { site to biorefineries }(\$ / \mathrm{t})\end{array}$ & $b_{i k}=3.85+0.085 *$ distance $_{i k}($ for all $i . k)$ \\
\hline [55] & $\begin{array}{c}\text { Cost of transporting biomass unit storage centers to } \\
\text { biorefineries }(\$ / \mathrm{t})\end{array}$ & $c_{j k}=3.85+0.085 *$ distance $_{j k}($ for all $j, k)$ \\
\hline [55] & $\begin{array}{l}\text { Cost of transporting a bioethanol unit from } \\
\text { biorefineries to mixing plants }(\$ / \mathrm{L} \times \mathrm{km})\end{array}$ & $d_{k m}=0.000028($ for all $k, m)$ \\
\hline [55] & $\begin{array}{c}\text { Cost of transporting a bioethanol unit from mixing } \\
\text { plants to customers }(\$ / \mathrm{L} \times \mathrm{km})\end{array}$ & $e_{m n}=0.000028($ for all $m, n)$ \\
\hline$[2,55]$ & Storage capacity of $s$ & $\mathrm{SA}_{j}=[110000$ \\
\hline [55] & Bioethanol productio & $\mathrm{SB}_{k}=[190,380,190] \mathrm{MLPY}$ \\
\hline Assumed & Capacity to store biomass per year in biorefineries $(\mathrm{t})$ & $\mathrm{SBB}_{k}=[0,0,0]($ for all $k)$ \\
\hline [56] & Capacity of the mixing plants (L) & $\mathrm{SM}_{m}=[370000000,555000000,370000000]$ (fo \\
\hline Assumed & mber of biorefine & $n b=3,($ for all $t)$ \\
\hline Assumed & Number of mixing plants that can be opened & $n m=3,($ for all $t)$ \\
\hline [59] & Cost per unit of fuel in the period $(\$ / \mathrm{L})$ & $\mu_{t}=1.00($ for all $t)$ \\
\hline & The processing cost of a biomass unit $(\$ / t)$ & $\omega_{k b}=48.86($ for all $b, k)$ \\
\hline Assumed & The proportion of land available at the harvest site & $P_{i b t}=1.00($ for all $i, b, t)$ \\
\hline$[58,60]$ & Reason for deterioration of stored biomass & $\theta(\%)=0.01(/ \mathrm{t})$ \\
\hline$[2,55]$ & Biomass conversion ratio $(\mathrm{L} / \mathrm{t})$ & $\lambda_{b}=[208.93,274.9]$ for all $t$ \\
\hline [55] & Dep & $\begin{array}{c}D_{n t} \text { is the demand that follows a normal distribution with a standard } \\
\text { deviation of } 15 \% \text { of the mean }\end{array}$ \\
\hline Assumed & Percentage destined to store biomass in a biorefinery & $\rho=0.26$ (for all $j$ \\
\hline
\end{tabular}

Next, numerical data are detailed only for the LA1 scenario, because, in this scenario, the best total cost of the Bio-Eth SC has been obtained. Table 5 provides the optimal allocation of harvest sites, storage center, biorefinery, and mixing plant to meet the demand of 988 MLPY with a mixture of $8 \%$ bioethanol.

Figure 13 shows the selected harvest sites, the storage center (capacity 110,000 t), biorefinery (capacity 190 MLPY), and mixing plant (555,000 MLPY).

According to Figure 13, the locations for the storage center, the biorefinery, and the mixing plant are selected by the model relative to the center where the greatest amount of agricultural residues of corn and barley is located.

Table 6 shows a breakdown of the costs (opening of facilities, harvest, transport, storage, processing, and fossil fuel) that would be necessary for the solution of the problem when there is a mixture of fossil fuel and bioethanol of E5,
E8, E11, E14, E17, and E20. The breakdown of the costs is indicated as a percentage concerning the total of the Bio-Eth SC. The proposed MILP model is sensitive to changes in the parameters indicated in Table 2.

From the case of study, it is determined that only the opening one storage center, one biorefinery, and one mixing plant are required. From the analysis of results, it is observed that the best cost of the Bio-Eth SC is for a production of E8. The cost per litre would be according to the mathematical model and the parameters provided of USD 0.99 to produce a bioethanol mixture E8, which for the case of the study region would be a price that could not compete with the current cost of the available fuel (USD 0.95) [61, 62]. The difference in costs of $4.2 \%$ leaves bioethanol produced from corn and barley residues biomass in the study region at a disadvantage. It leads us to the reflection that, in order to be profitable, it would be necessary to guarantee a higher yield 
TABle 3: Geographical coordinates.

\begin{tabular}{|c|c|c|c|c|c|}
\hline \multicolumn{2}{|r|}{ Harvest sites $(i)$} & \multicolumn{4}{|c|}{ Customers $(n)$} \\
\hline 1 & Acatlán, HGO & $20.1404043,-98.4450531$ & 48 & $6262620-13$ & $\begin{array}{l}\text { 19.82661012, } \\
-98.9775187\end{array}$ \\
\hline 2 & Acaxochitlán, HGO & $20.1520077,-98.1909943$ & 49 & $6263159-13$ & $\begin{array}{c}19.83591093 \\
-98.98033248\end{array}$ \\
\hline 3 & Actopan, HGO & $20.2987486,-98.9782333$ & 50 & $1598437-13$ & $\begin{array}{r}20.07419562 \\
-98.35160175\end{array}$ \\
\hline 4 & Agua Blanca de Iturbide, HGO & $20.3394764,-98.3568192$ & 51 & $6262645-13$ & $\begin{array}{c}\text { 20.12329479, } \\
-98.73474466\end{array}$ \\
\hline 5 & Ajacuba, HGO & $20.0959165,-99.119339$ & 52 & $6740313-13$ & $\begin{array}{l}20.04649645 \\
-98.79130317\end{array}$ \\
\hline 6 & Almoloya, HGO & $19.709829,-98.406601$ & 53 & $1621660-13$ & $\begin{array}{r}20.11721674 \\
-98.78123335\end{array}$ \\
\hline 7 & Apan, HGO & $19.7040111,-98.4399033$ & 54 & $6335388-13$ & $\begin{array}{r}20.26118942 \\
-98.94301898\end{array}$ \\
\hline 8 & Atotonilco el Grande, HGO & $20.2850629,-98.6824608$ & 55 & $1621474-13$ & $\begin{array}{l}20.1242314 \\
-98.775894\end{array}$ \\
\hline 9 & Cuautepec de Hinojosa, HGO & $20.0235164,-98.3107281$ & 56 & $1621095-13$ & $\begin{array}{r}20.12485259 \\
-98.75948145\end{array}$ \\
\hline 10 & El Arenal, HGO & $20.2201604,-98.9181519$ & 57 & $1617639-13$ & $\begin{array}{c}20.12630144 \\
-98.74515474\end{array}$ \\
\hline 11 & Emiliano Zapata, HGO & $19.6674831,-98.5477066$ & 58 & $1534402-13$ & $\begin{array}{c}20.0960579 \\
-98.36573475\end{array}$ \\
\hline 12 & Epazoyucan, HGO & $20.0207745,-98.6423779$ & 59 & $6205904-13$ & $\begin{array}{r}20.07958387 \\
-98.38479625\end{array}$ \\
\hline 13 & Francisco I. Madero, HGO & $20.2312746,-99.1032028$ & 60 & $1600012-13$ & $\begin{array}{r}20.09195465 \\
-98.75451949\end{array}$ \\
\hline 14 & Huasca de Ocampo, HGO & $20.2040916,-98.5725117$ & 61 & $1539674-13$ & $\begin{array}{r}20.06446449 \\
-98.36362082\end{array}$ \\
\hline 15 & Huehuetla, HGO & $20.4554836,-98.0729771$ & 62 & $1554609-13$ & $\begin{array}{c}\text { 20.0684327, } \\
-98.36396313\end{array}$ \\
\hline 16 & Metepec, HGO & $20.2477835,-98.312273$ & 63 & $1599977-13$ & $\begin{array}{r}20.09458374 \\
-98.76079014\end{array}$ \\
\hline 17 & Metztitlán, HGO & $20.5921342,-98.7703514$ & 64 & 6740993-13 & $\begin{array}{r}19.97945331 \\
-98.51887974\end{array}$ \\
\hline 18 & Mineral de la Reforma, HGO & $20.0406116,-98.7353325$ & 65 & $1608382-13$ & $\begin{array}{c}20.24632181 \\
-99.09955346\end{array}$ \\
\hline 19 & Mineral del Chico, HGO & $20.2134753,-98.7344742$ & 66 & $6262729-13$ & $\begin{array}{r}20.28812662 \\
-98.67235631\end{array}$ \\
\hline 20 & Mineral del Monte, HGO & $20.1323459,-98.6602306$ & 67 & $1608392-13$ & $\begin{array}{l}20.24287894 \\
-99.08429399\end{array}$ \\
\hline 21 & Omitlán de Juárez, HGO & $20.1724325,-98.6513042$ & 68 & $1599140-13$ & $\begin{array}{c}20.037941 \\
-98.31412473\end{array}$ \\
\hline 22 & Pachuca de Soto, HGO & $20.077215,-98.7566185$ & 69 & $1569036-13$ & $\begin{array}{c}20.05524019 \\
-98.78057667\end{array}$ \\
\hline 23 & San Agustín Metzquititlán, HGO & $20.5296116,-98.6427212$ & 70 & $1535971-13$ & $\begin{array}{r}20.10715881 \\
-98.74712817\end{array}$ \\
\hline 24 & San Agustín Tlaxiaca, HGO & $20.1226752,-98.8809013$ & 71 & $1539895-13$ & $\begin{array}{c}20.07733171 \\
-98.37286078\end{array}$ \\
\hline 25 & San Bartolo Tutotepec, HGO & $20.3929053,-98.1869602$ & 72 & $1522614-13$ & $\begin{array}{r}20.08003779 \\
-98.74534313\end{array}$ \\
\hline 26 & San Salvador, HGO & $20.2840163,-99.0279293$ & 73 & $1526786-13$ & $\begin{array}{c}20.1586768 \\
-98.20283419\end{array}$ \\
\hline 27 & Santiago de Anaya, HGO & $20.3781015,-98.9691353$ & 74 & $1524903-13$ & $\begin{array}{l}20.34212311 \\
-98.35927666\end{array}$ \\
\hline 28 & $\begin{array}{c}\text { Santiago Tulantepec de Lugo Guerrero, } \\
\text { HGO }\end{array}$ & $20.0438369,-98.3662605$ & 75 & $1521604-13$ & $\begin{array}{r}20.09596989 \\
-98.71567676\end{array}$ \\
\hline 29 & Singuilucan, HGO & $19.969154,-98.5313988$ & 76 & $1598897-13$ & $\begin{array}{r}20.07360652 \\
-98.35076155\end{array}$ \\
\hline 30 & Tenango de Doria, HGO & $20.3341848,-98.2233524$ & 77 & $1595031-13$ & $\begin{array}{c}20.11110651 \\
-98.72523034\end{array}$ \\
\hline 31 & Tepeapulco, HGO & $19.7975156,-98.5589504$ & 78 & $6335903-13$ & $\begin{array}{l}20.27999636 \\
-98.96093552\end{array}$ \\
\hline
\end{tabular}


TABle 3: Continued.

\begin{tabular}{|c|c|c|c|c|c|}
\hline \multicolumn{2}{|r|}{ Harvest sites $(i)$} & \multicolumn{4}{|c|}{ Customers $(n)$} \\
\hline 32 & Tianguistengo, HGO & $20.723284,-98.6386013$ & 79 & $1620940-13$ & $\begin{array}{r}20.03455212 \\
-98.79921647\end{array}$ \\
\hline 33 & Tizayuca, HGO & $19.8884631,-98.9345455$ & 80 & $6335945-13$ & $\begin{array}{l}19.8339404 \\
-98.94186277\end{array}$ \\
\hline 34 & Tlanalapa, HGO & $19.8313091,-98.5988617$ & 81 & $6335902-13$ & $\begin{array}{c}20.2856335 \\
-99.01319879\end{array}$ \\
\hline 35 & Tolcayuca, HGO & $19.952293,-98.9093113$ & 82 & $1555860-13$ & $\begin{array}{l}20.01385899 \\
-98.6385266\end{array}$ \\
\hline 36 & Tulancingo de Bravo, HGO & $20.0986571,-98.4009361$ & 83 & $6762186-13$ & $\begin{array}{r}19.66603204 \\
-98.55074321\end{array}$ \\
\hline 37 & Villa de Tezontepec, HGO & $19.8965341,-98.8326645$ & 84 & $1538923-13$ & $\begin{array}{c}20.10591305 \\
-98.75064516\end{array}$ \\
\hline 38 & Zacualtipán de Ángeles, HGO & $20.6435475,-98.642292$ & 85 & $6262726-13$ & $\begin{array}{r}20.03290592 \\
-98.30909565\end{array}$ \\
\hline 39 & Zapotlán de Juárez, HGO & $19.9717354,-98.8762665$ & 86 & $6263199-13$ & $\begin{array}{c}20.06539773 \\
-98.34350094\end{array}$ \\
\hline 40 & Zempoala, HGO & $19.9207444,-98.6840057$ & 87 & $1555405-13$ & $\begin{array}{c}20.0328635 \\
-98.30902557\end{array}$ \\
\hline 41 & Axapusco, MEX & $19.7351988,-98.7664032$ & 88 & $1521678-13$ & $\begin{array}{l}20.08542351 \\
-98.7193632\end{array}$ \\
\hline 42 & Hueypoxtla, MEX & $19.9013764,-99.0860367$ & 89 & $6735744-13$ & $\begin{array}{c}20.3746293 \\
-99.05216038\end{array}$ \\
\hline 43 & Nopaltepec, MEX & $19.7837458,-98.7245178$ & 90 & $1596483-13$ & $\begin{array}{c}20.10452107 \\
-98.74505785\end{array}$ \\
\hline 44 & Otumba, MEX & $19.7091826,-98.7348175$ & 91 & $1597383-13$ & $\begin{array}{l}20.09837895 \\
-98.7613604\end{array}$ \\
\hline 45 & San Martín de las Pirámides, MEX & $19.7069201,-98.8124084$ & 92 & $6336069-13$ & $\begin{array}{r}19.83060211 \\
-98.97878862\end{array}$ \\
\hline 46 & Tecámac, MEX & $19.730513,-98.9758301$ & 93 & $6336067-13$ & $\begin{array}{r}20.09833665 \\
-98.76131585\end{array}$ \\
\hline 47 & Temascalapa, MEX & $19.8170981,-98.8851929$ & 94 & $6335919-13$ & $\begin{array}{r}20.21798028 \\
-98.91084482\end{array}$ \\
\hline 48 & Teotihuacán, MEX & $19.6594005,-98.8419342$ & 95 & $6335882-13$ & $\begin{array}{l}19.77797253 \\
-98.5807555\end{array}$ \\
\hline 49 & Tepetlaoxtoc, MEX & $19.5722448,-98.8036537$ & 96 & $6709345-13$ & $\begin{array}{c}\text { 20.08941813, } \\
-98.34905726\end{array}$ \\
\hline 50 & Zumpango, MEX & $19.7822113,-99.0850067$ & 97 & $1602424-13$ & $\begin{array}{r}19.78370454 \\
-98.57802137\end{array}$ \\
\hline 51 & Ahuacatlán, PUE & $20.0077903,-97.8598595$ & 98 & $1614387-13$ & $\begin{array}{c}19.7035096 \\
-98.46552883\end{array}$ \\
\hline 52 & Ahuazotepec, PUE & $20.0403697,-98.1574345$ & 99 & $6262785-13$ & $\begin{array}{c}20.08400245 \\
-98.72474423\end{array}$ \\
\hline 53 & Amixtlán, PUE & $20.051658,-97.7990055$ & 100 & $1580536-13$ & $\begin{array}{r}19.80990315 \\
-98.59875873\end{array}$ \\
\hline 54 & Aquixtla, PUE & $19.7986866,-97.93612$ & 101 & $6434004-13$ & $\begin{array}{c}20.1405897 \\
-98.69136054\end{array}$ \\
\hline 55 & Camocuautla, PUE & $20.0360961,-97.7580643$ & 102 & $6262651-13$ & $\begin{array}{c}20.10395531 \\
-98.76725522\end{array}$ \\
\hline 56 & Chiconcuautla, PUE & $20.085639,-97.9413986$ & 103 & $6263077-13$ & $\begin{array}{c}20.11468896 \\
-98.76232766\end{array}$ \\
\hline 57 & Chignahuapan, PUE & $19.8149987,-98.0056$ & 104 & $1536452-13$ & $\begin{array}{r}19.97331851 \\
-98.52315017\end{array}$ \\
\hline 58 & Coatepec, PUE & $20.0561731,-97.7322292$ & 105 & $6262609-13$ & $\begin{array}{c}20.0946648 \\
-98.36282552\end{array}$ \\
\hline 59 & Cuautempan, PUE & $19.9108993,-97.7914524$ & 106 & $6263141-13$ & $\begin{array}{r}20.09469545 \\
-98.36277611\end{array}$ \\
\hline 60 & Hermenegildo Galeana, PUE & $20.1154218,-97.7491379$ & 107 & $6741127-13$ & $\begin{array}{l}20.34702497 \\
-99.03073337\end{array}$ \\
\hline 61 & Honey, PUE & $20.2421465,-98.2128167$ & 108 & $6335877-13$ & $\begin{array}{c}19.91021142 \\
-98.67579737\end{array}$ \\
\hline
\end{tabular}


TABle 3: Continued.

\begin{tabular}{|c|c|c|c|c|c|}
\hline \multicolumn{2}{|r|}{ Harvest sites $(i)$} & \multicolumn{4}{|c|}{ Customers $(n)$} \\
\hline 62 & Huauchinango, PUE & $20.1864906,-98.048172$ & 109 & $6336081-13$ & $\begin{array}{l}20.08969037 \\
-98.7715266\end{array}$ \\
\hline 63 & Hueytlalpan, PUE & $20.0250486,-97.7016735$ & 110 & $6335909-13$ & $19.75428933,-98.588776$ \\
\hline 64 & Huitzilan de Serdán, PUE & $19.9690733,-97.6893139$ & 111 & $6434025-13$ & $\begin{array}{l}20.10238345 \\
-98.71881908\end{array}$ \\
\hline 65 & Ixtacamaxtitlán, PUE & $19.6214879,-97.8187466$ & 112 & $6263013-13$ & $\begin{array}{r}20.06923509 \\
-98.36501259\end{array}$ \\
\hline 66 & Jalpan, PUE & $20.4750844,-97.9430079$ & 113 & $1539450-13$ & $\begin{array}{c}20.10114731 \\
-98.74675649\end{array}$ \\
\hline 67 & Jopala, PUE & $20.1675582,-97.6928329$ & 114 & $6335912-13$ & $\begin{array}{r}19.78847457 \\
-98.55422289\end{array}$ \\
\hline 68 & Juan Galindo, PUE & $20.2059039,-98.0024242$ & 115 & $1536575-13$ & $\begin{array}{l}\text { 19.9731704, } \\
-98.52329416\end{array}$ \\
\hline 69 & Naupan, PUE & $20.2340531,-98.1076097$ & 116 & $1616878-13$ & $\begin{array}{c}20.1174499 \\
-98.89376353\end{array}$ \\
\hline 70 & Olintla, PUE & $20.1091352,-97.6866531$ & 117 & $1571974-13$ & $\begin{array}{l}20.09383484 \\
-99.12531276\end{array}$ \\
\hline 71 & Pahuatlán, PUE & $20.2785417,-98.1446457$ & 118 & $1556421-13$ & $\begin{array}{c}20.06768121 \\
-98.41469264\end{array}$ \\
\hline 72 & Pantepec, PUE & $20.5216538,-97.9353046$ & 119 & $6262701-13$ & $\begin{array}{r}20.65042693 \\
-98.64842803\end{array}$ \\
\hline 73 & San Felipe Tepatlán, PUE & $20.0892362,-97.7964735$ & 120 & $6205976-13$ & $\begin{array}{c}19.84031009 \\
-98.97275088\end{array}$ \\
\hline 74 & Tepango de Rodríguez, PUE & $20.0028705,-97.7874613$ & 121 & $6335360-13$ & $\begin{array}{c}20.1100385 \\
-98.75335167\end{array}$ \\
\hline 75 & Tepetzintla, PUE & $19.9646162,-97.8445172$ & 122 & $1620830-13$ & $\begin{array}{r}20.04193946 \\
-98.79443138\end{array}$ \\
\hline 76 & Tetela de Ocampo, PUE & $19.8114457,-97.8171158$ & 123 & $1607307-13$ & $\begin{array}{l}20.27346352 \\
-98.9503825\end{array}$ \\
\hline 77 & Tlacuilotepec, PUE & $20.3274443,-98.0664539$ & 124 & E00684-13 & $20.120477,-98.740764$ \\
\hline 78 & Tlaola, PUE & $20.1335547,-97.9192543$ & 125 & E00719-13 & $19.984757,-98.62337$ \\
\hline 79 & Tlapacoya, PUE & $20.1190485,-97.8497314$ & 126 & E00723-13 & $19.788618,-98.55419$ \\
\hline 80 & Tlaxco, PUE & $20.4193312,-98.0314136$ & 127 & E03499-13 & $20.148356,-98.440038$ \\
\hline 81 & Xicotepec, PUE & $20.2628413,-97.9676628$ & 128 & E04488-13 & $20.135759,-98.88477$ \\
\hline 82 & Xochitlán de Vicente Suárez, PUE & $19.9625389,-97.6282883$ & 129 & E04911-13 & $20.147214,-98.294567$ \\
\hline 83 & Zacatlán, PUE & $19.9289751,-97.9427719$ & 130 & E05105-13 & $20.101092,-98.747201$ \\
\hline 84 & Zapotitlán de Méndez, PUE & $19.9989588,-97.7088833$ & 131 & E05712-13 & $19.989644,-98.706489$ \\
\hline 85 & Zihuateutla, PUE & $20.2555541,-97.8935051$ & 132 & E07143-13 & $19.6689,-98.3736$ \\
\hline 86 & Zongozotla, PUE & $19.9726631,-97.7253628$ & 133 & E07168-13 & $19.879804,-98.947654$ \\
\hline 87 & Atlangatepec, TLAX & $19.5321276,-98.2013798$ & 134 & E07373-13 & $20.253956,-98.99411$ \\
\hline 88 & Benito Juárez, TLAX & $19.5832429,-98.4103775$ & 135 & E07425-13 & $20.092882,-98.762251$ \\
\hline 89 & Calpulalpan, TLAX & $19.585022,-98.5506248$ & 136 & E07555-13 & $19.834483,-98.94162$ \\
\hline 90 & Emiliano Zapata, TLAX & $19.5532389,-97.9195118$ & 137 & E07857-13 & $20.0002,-98.3003$ \\
\hline 91 & Españita, TLAX & $19.4551006,-98.4193897$ & 138 & E07928-13 & $20.0381,-98.3141$ \\
\hline 92 & Hueyotlipan, TLAX & $19.4686558,-98.3388805$ & 139 & E08197-13 & $20.28471,-98.944501$ \\
\hline 93 & Lázaro Cárdenas, TLAX & $19.5432094,-97.9921246$ & 140 & E08798-13 & $20.085281,-98.718168$ \\
\hline 94 & Muñoz de Domingo Arenas, TLAX & $19.4747654,-98.2139111$ & 141 & E08812-13 & $20.07401,-98.35171$ \\
\hline 95 & Nanacamilpa de Mariano Arista, TLAX & $19.4862556,-98.5553455$ & 142 & E09581-13 & $20.010591,-98.821619$ \\
\hline 96 & San Lucas Tecopilco, TLAX & $19.4870648,-98.2511616$ & 143 & E09784-13 & $19.850734,-98.974847$ \\
\hline 97 & Sanctórum de Lázaro Cárdenas, TLAX & $19.4869839,-98.4641075$ & 144 & E12016-13 & $20.0802139,-98.7874528$ \\
\hline 98 & Tetla de la Solidaridad, TLAX & $19.4615749,-98.0677414$ & 145 & $2197248-15$ & $\begin{array}{c}19.70193184 \\
-98.75508293\end{array}$ \\
\hline 99 & Tlaxco, TLAX & $19.6306234,-98.1286812$ & 146 & $2014301-15$ & $\begin{array}{r}19.86693441 \\
-99.04652651\end{array}$ \\
\hline 100 & Xaltocan, TLAX & $19.4285129,-98.2227945$ & 147 & $6346818-15$ & $\begin{array}{r}19.72031508 \\
-98.97158131\end{array}$ \\
\hline 101 & Benito Juárez, VER & $20.8727669,-98.1990623$ & 148 & $2197269-15$ & $\begin{array}{l}19.79278912 \\
-99.0755245\end{array}$ \\
\hline 102 & Coahuitlán, VER & $20.2572451,-97.7290964$ & 149 & 2197251-15 & $\begin{array}{r}19.68797719 \\
-98.98854169\end{array}$ \\
\hline
\end{tabular}


TABle 3: Continued.

\begin{tabular}{|c|c|c|c|c|c|}
\hline \multicolumn{2}{|r|}{ Harvest sites $(i)$} & \multicolumn{4}{|c|}{ Customers $(n)$} \\
\hline 103 & Coyutla, VER & $20.2521319,-97.6707745$ & 150 & $6207947-15$ & $19.9653928,-99.0418919$ \\
\hline 104 & Filomeno Mata, VER & $20.205622,-97.709012$ & 151 & $6207948-15$ & $\begin{array}{c}19.91509476 \\
-99.07476651\end{array}$ \\
\hline 105 & Huayacocotla, VER & $20.5440793,-98.4877968$ & 152 & $2197255-15$ & $\begin{array}{r}19.56755307 \\
-98.81903485\end{array}$ \\
\hline 106 & Ilamatlán, VER & $20.7772208,-98.4431648$ & 153 & $2197252-15$ & $\begin{array}{r}19.74904928 \\
-98.94827453\end{array}$ \\
\hline 107 & Ixhuatlán de Madero, VER & $20.6904469,-98.0195045$ & 154 & $2197253-15$ & $\begin{array}{c}\text { 19.68168016, } \\
-98.97692368\end{array}$ \\
\hline 108 & Mecatlán, VER & $20.2060248,-97.6806021$ & 155 & $2197254-15$ & $\begin{array}{r}\text { 19.65975096, } \\
-99.00496648\end{array}$ \\
\hline 109 & Texcatepec, VER & $20.5797603,-98.360424$ & 156 & $2197250-15$ & $\begin{array}{r}19.70223242 \\
-98.76409917\end{array}$ \\
\hline 110 & Tlachichilco, VER & $20.6238679,-98.1966805$ & 157 & $2267640-15$ & $\begin{array}{c}19.66808917 \\
-99.00412379\end{array}$ \\
\hline 111 & Zacualpan, VER & $20.4345332,-98.3421421$ & 158 & $2244535-15$ & $\begin{array}{l}\text { 19.82544515 } \\
-99.0893007\end{array}$ \\
\hline 112 & Zontecomatlán de López y Fuentes, VER & $20.7610699,-98.3384728$ & 159 & $6698477-15$ & $\begin{array}{c}19.82165512 \\
-99.08128257\end{array}$ \\
\hline $\begin{array}{l}\text { Storage centers } \\
(j)\end{array}$ & & & 160 & $6757467-15$ & $\begin{array}{l}\text { 19.81995999, } \\
-99.11503166\end{array}$ \\
\hline 1 & San Agustín Tlaxiaca & $20.1275913,-98.9911079$ & 161 & $6346751-15$ & $\begin{array}{c}\text { 19.80429001, } \\
-99.10600887\end{array}$ \\
\hline 2 & Zempoala & $19.9731069,-98.701172$ & 162 & $2197249-15$ & $\begin{array}{r}\text { 19.70159876, } \\
-98.75514275\end{array}$ \\
\hline 3 & Apan & $19.6783131,-98.391838$ & 163 & 2244511-15 & $19.81314884,-99.1096896$ \\
\hline 4 & Tlaola & $20.1092159,-97.8980541$ & 164 & $6207949-15$ & $\begin{array}{c}19.6659576 \\
-99.01491448\end{array}$ \\
\hline 5 & San Agustín Metzquititlán & $20.4334477,-98.6826325$ & 165 & $6727603-15$ & $\begin{array}{r}19.65450225 \\
-99.01940473\end{array}$ \\
\hline 6 & Tulancingo & $20.2029237,-98.3159637$ & 166 & $6711512-15$ & $\begin{array}{l}\text { 19.77085433, } \\
-98.9783269\end{array}$ \\
\hline 7 & Zacatlán & $19.9322026,-98.0739212$ & 167 & $6712662-15$ & $\begin{array}{c}19.65768324 \\
-99.01904667\end{array}$ \\
\hline Biorefineries $(k)$ & & & 168 & $6348476-15$ & $\begin{array}{l}19.66849959 \\
-99.0040818\end{array}$ \\
\hline 1 & Zempoala & $19.89299,-98.66667$ & 169 & $6207760-15$ & $19.88531279,-98.865927$ \\
\hline 2 & Santa Ana Hueytlalpan & $20.15845,-98.28231$ & 170 & $6705119-15$ & $\begin{array}{c}\text { 19.67291216, } \\
-99.02770086\end{array}$ \\
\hline 3 & Actopan & $20.26992,-98.85772$ & 171 & 1974519-15 & $\begin{array}{c}19.67362317 \\
-99.02787736\end{array}$ \\
\hline Mixing plants $(m)$ & & & 172 & $6265433-15$ & $\begin{array}{c}19.68830299 \\
-98.82640382\end{array}$ \\
\hline 1 & Tolacayuca & $19.93496,-98.89119$ & 173 & $6265464-15$ & $\begin{array}{c}\text { 19.65220143, } \\
-99.00490701\end{array}$ \\
\hline 2 & Sahagún & $19.74763,-98.58444$ & 174 & $6730375-15$ & $\begin{array}{c}19.82697719 \\
-98.89847154\end{array}$ \\
\hline 3 & Tulancingo & $20.14878,-98.36059$ & 175 & $6348771-15$ & $\begin{array}{r}19.81263783 \\
-99.10890691\end{array}$ \\
\hline Customers $(n)$ & & & 176 & $6347662-15$ & $\begin{array}{c}19.96500515 \\
-99.04159129\end{array}$ \\
\hline 1 & $6701141-13$ & $\begin{array}{c}20.07655101 \\
-98.38707515\end{array}$ & 177 & E08836-15 & $19.775684,-99.014942$ \\
\hline 2 & $1615495-13$ & $\begin{array}{l}19.70987382 \\
-98.3977008\end{array}$ & 178 & E10339-15 & $19.704131,-98.945184$ \\
\hline 3 & 6720392-13 & $\begin{array}{c}20.12422462 \\
-98.77604748\end{array}$ & 179 & E10524-15 & $19.650044,-98.90331$ \\
\hline 4 & 6335409-13 & $\begin{array}{c}20.10793091 \\
-98.71701937\end{array}$ & 180 & E12702-15 & $19.7073,-98.70479$ \\
\hline
\end{tabular}


TABle 3: Continued.

\begin{tabular}{|c|c|c|c|c|c|}
\hline \multicolumn{2}{|c|}{ Harvest sites $(i)$} & \multicolumn{4}{|c|}{ Customers $(n)$} \\
\hline 5 & 6336448-13 & $\begin{array}{c}20.12485355 \\
-98.75951003\end{array}$ & 181 & 6380203-21 & $\begin{array}{r}19.97722214 \\
-98.05722221\end{array}$ \\
\hline 6 & 6263019-13 & $\begin{array}{c}20.05575529 \\
-98.78654483\end{array}$ & 182 & 6380204-21 & $\begin{array}{c}19.94760996 \\
-97.96174374\end{array}$ \\
\hline 7 & $6740451-13$ & $\begin{array}{l}20.09373122 \\
-98.7564247\end{array}$ & 183 & $6377502-21$ & $\begin{array}{r}19.92502054 \\
-97.97023985\end{array}$ \\
\hline 8 & $6263079-13$ & $\begin{array}{r}20.10597482 \\
-98.75783492\end{array}$ & 184 & $6725338-21$ & $\begin{array}{r}20.00717687 \\
-97.85922537\end{array}$ \\
\hline 9 & 6516088-13 & $\begin{array}{c}20.0809349 \\
-98.38392419\end{array}$ & 185 & $3278184-21$ & $\begin{array}{c}20.18189292 \\
-98.03584042\end{array}$ \\
\hline 10 & 1513628-13 & $\begin{array}{l}20.6628722 \\
-98.66316875\end{array}$ & 186 & $6710748-21$ & $\begin{array}{c}19.62174176 \\
-97.81312585\end{array}$ \\
\hline 11 & $1601800-13$ & $\begin{array}{c}19.91033841 \\
-98.67584542\end{array}$ & 187 & 6377024-21 & $\begin{array}{c}19.94185103 \\
-97.96607548\end{array}$ \\
\hline 12 & $6335272-13$ & $\begin{array}{c}20.26979962 \\
-98.94978937\end{array}$ & 188 & 6379891-21 & $\begin{array}{c}19.89416659 \\
-97.97277779\end{array}$ \\
\hline 13 & $1620330-13$ & $\begin{array}{c}20.0543211 \\
-98.78778484\end{array}$ & 189 & 6448431-21 & $\begin{array}{c}20.17338613 \\
-98.05862044\end{array}$ \\
\hline 14 & $6336345-13$ & $\begin{array}{c}20.07531934 \\
-98.78202543\end{array}$ & 190 & $6710369-21$ & $\begin{array}{c}19.91936676 \\
-97.96005073\end{array}$ \\
\hline 15 & 1600594-13 & $\begin{array}{c}20.06303633 \\
-98.77364756\end{array}$ & 191 & $3417636-21$ & $\begin{array}{c}20.38523593 \\
-97.88377247\end{array}$ \\
\hline 16 & $6335700-13$ & $\begin{array}{l}20.07754875 \\
-98.37119607\end{array}$ & 192 & $3284800-21$ & $\begin{array}{c}20.20412811 \\
-97.98910088\end{array}$ \\
\hline 17 & 6263097-13 & $\begin{array}{c}20.08406802 \\
-98.37592946\end{array}$ & 193 & 6379274-21 & $\begin{array}{c}20.13753714 \\
-98.09779566\end{array}$ \\
\hline 18 & $6263098-13$ & $\begin{array}{c}20.05705164 \\
-98.75920889\end{array}$ & 194 & 6741034-21 & $\begin{array}{c}20.17512032 \\
-98.06730308\end{array}$ \\
\hline 19 & 6418291-13 & $\begin{array}{c}20.04763493 \\
-98.35911669\end{array}$ & 195 & $6271508-21$ & $\begin{array}{c}20.26676393 \\
-97.9601726\end{array}$ \\
\hline 20 & 1546866-13 & $\begin{array}{c}20.27901369 \\
-98.64926589\end{array}$ & 196 & $6271865-21$ & $\begin{array}{c}20.26195257 \\
-97.96239184\end{array}$ \\
\hline 21 & 1532906-13 & $\begin{array}{c}20.12054938 \\
-98.74042411\end{array}$ & 197 & $3502442-21$ & $\begin{array}{c}19.81856774 \\
-97.81079527\end{array}$ \\
\hline 22 & 1619576-13 & $\begin{array}{c}\text { 19.95534078, } \\
-98.91790267\end{array}$ & 198 & $3297403-21$ & $\begin{array}{c}19.84155845 \\
-98.03226973\end{array}$ \\
\hline 23 & 1539469-13 & $\begin{array}{c}\text { 19.8483681, } \\
-98.97330671\end{array}$ & 199 & 6378263-21 & $\begin{array}{c}20.27395137 \\
-97.96405384\end{array}$ \\
\hline 24 & 1539471-13 & $\begin{array}{r}19.88013765 \\
-98.94654865\end{array}$ & 200 & $3287035-21$ & $\begin{array}{c}20.00394441 \\
-97.80046494\end{array}$ \\
\hline 25 & 1539473-13 & $\begin{array}{r}\text { 19.83932874, } \\
-98.97307341\end{array}$ & 201 & E00751-21 & $20.173404,-98.059527$ \\
\hline 26 & 1539476-13 & $\begin{array}{r}\text { 19.85091693 } \\
-98.97516152\end{array}$ & 202 & 6311273-29 & $\begin{array}{c}\text { 19.55175573, } \\
-98.49455764\end{array}$ \\
\hline 27 & 1539453-13 & $\begin{array}{c}20.07313391 \\
-98.79250195\end{array}$ & 203 & 6311274-29 & $\begin{array}{c}19.54532657 \\
-98.49260474\end{array}$ \\
\hline 28 & 6336611-13 & $\begin{array}{c}20.06621245 \\
-98.77011166\end{array}$ & 204 & 6459714-29 & $\begin{array}{c}19.43025706 \\
-98.13472193\end{array}$ \\
\hline 29 & 6335523-13 & $\begin{array}{c}20.11312044 \\
-98.74341589\end{array}$ & 205 & 6756853-29 & $\begin{array}{r}19.48422352 \\
-98.11410177\end{array}$ \\
\hline 30 & 6719681-13 & $20.11237991,-98.4051467$ & 206 & $4168017-29$ & $\begin{array}{r}19.58633359 \\
-98.42847233\end{array}$ \\
\hline 31 & 6740924-13 & $\begin{array}{r}20.07298533 \\
-98.37668807\end{array}$ & 207 & 4168020-29 & $\begin{array}{r}19.59175344 \\
-98.56376007\end{array}$ \\
\hline 32 & 1539449-13 & $\begin{array}{l}20.11643541 \\
-98.72615811\end{array}$ & 208 & $4168027-29$ & $\begin{array}{l}19.48210098 \\
-98.29439608\end{array}$ \\
\hline 33 & 6205931-13 & $\begin{array}{l}19.88237884 \\
-98.8220836\end{array}$ & 209 & 6406157-29 & $\begin{array}{c}19.49502059 \\
-98.53402659\end{array}$ \\
\hline 34 & 1539479-13 & $\begin{array}{r}20.07678617 \\
-98.38717142\end{array}$ & 210 & $4165224-29$ & $\begin{array}{r}19.49905295 \\
-98.05346502\end{array}$ \\
\hline
\end{tabular}


TABle 3: Continued.

\begin{tabular}{|c|c|c|c|c|c|}
\hline \multicolumn{2}{|c|}{ Harvest sites $(i)$} & \multicolumn{4}{|c|}{ Customers $(n)$} \\
\hline 35 & 1539429-13 & $\begin{array}{r}20.28485082 \\
-98.94467205\end{array}$ & 211 & 4209484-29 & $\begin{array}{c}19.42156402 \\
-98.21178823\end{array}$ \\
\hline 36 & 6434169-13 & $\begin{array}{c}20.11524358 \\
-98.40865361\end{array}$ & 212 & $4202637-29$ & $\begin{array}{c}19.4757085 \\
-98.11284982\end{array}$ \\
\hline 37 & $6205930-13$ & $\begin{array}{c}20.09476731 \\
-98.71836192\end{array}$ & 213 & $4202660-29$ & $\begin{array}{l}19.46469034 \\
-98.1132248\end{array}$ \\
\hline 38 & $6335577-13$ & $\begin{array}{r}20.09923999 \\
-98.71605545\end{array}$ & 214 & $6421897-29$ & $\begin{array}{c}19.58582813 \\
-98.54359179\end{array}$ \\
\hline 39 & $1539440-13$ & $\begin{array}{r}20.06872425 \\
-98.71708094\end{array}$ & 215 & $4161233-29$ & $\begin{array}{c}19.47311459 \\
-98.20562485\end{array}$ \\
\hline 40 & 6335571-13 & $\begin{array}{r}20.27545886 \\
-98.94117179\end{array}$ & 216 & 6406128-29 & $\begin{array}{c}19.59257433 \\
-98.57695318\end{array}$ \\
\hline 41 & $1539442-13$ & $\begin{array}{r}20.08646088 \\
-98.71297338\end{array}$ & 217 & 6405983-29 & $\begin{array}{c}19.58675979 \\
-98.54644898\end{array}$ \\
\hline 42 & $1539465-13$ & $\begin{array}{c}19.78297162 \\
-98.54409519\end{array}$ & 218 & $4207147-29$ & $\begin{array}{c}19.59273099 \\
-98.57614489\end{array}$ \\
\hline 43 & $1539462-13$ & $\begin{array}{c}20.28324963 \\
-99.01676083\end{array}$ & 219 & 6406051-29 & $\begin{array}{l}\text { 19.61164624, } \\
-98.11998572\end{array}$ \\
\hline 44 & $6262874-13$ & $\begin{array}{l}20.08409757 \\
-98.3759223\end{array}$ & 220 & $4168036-29$ & $\begin{array}{c}19.47516948 \\
-98.11276603\end{array}$ \\
\hline 45 & 1539444-13 & $\begin{array}{c}20.0583287 \\
-98.76038144\end{array}$ & 221 & E09430-29 & $19.5916714,-98.563885$ \\
\hline 46 & 1539455-13 & $\begin{array}{c}\text { 20.10272155, } \\
-98.74669701\end{array}$ & 222 & $4442880-30$ & $\begin{array}{l}20.52882643 \\
-98.49111013\end{array}$ \\
\hline 47 & 6205973-13 & $\begin{array}{l}19.83658241 \\
-98.9548442\end{array}$ & 223 & 4459848-30 & $\begin{array}{c}20.5829879 \\
-98.36571903\end{array}$ \\
\hline & & & 224 & $4460757-30$ & $20.77874,-98.44443$ \\
\hline
\end{tabular}

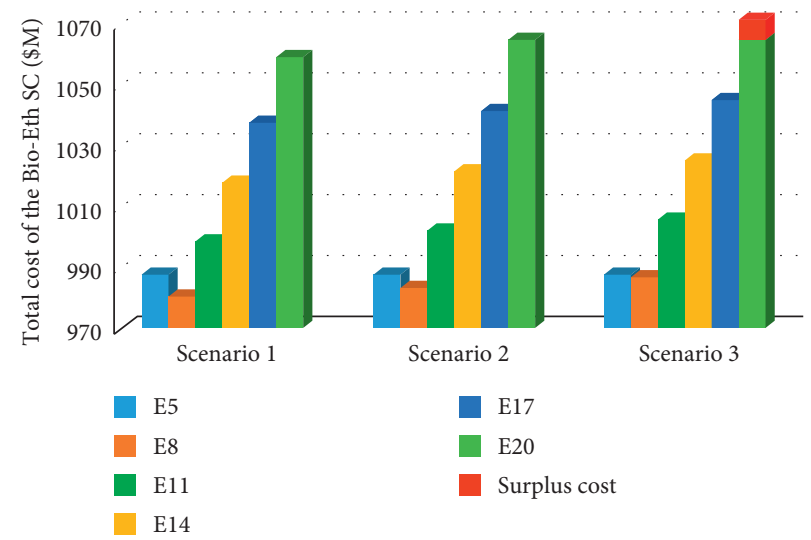

Figure 6: The total cost of Bio-Eth SC for three scenarios.

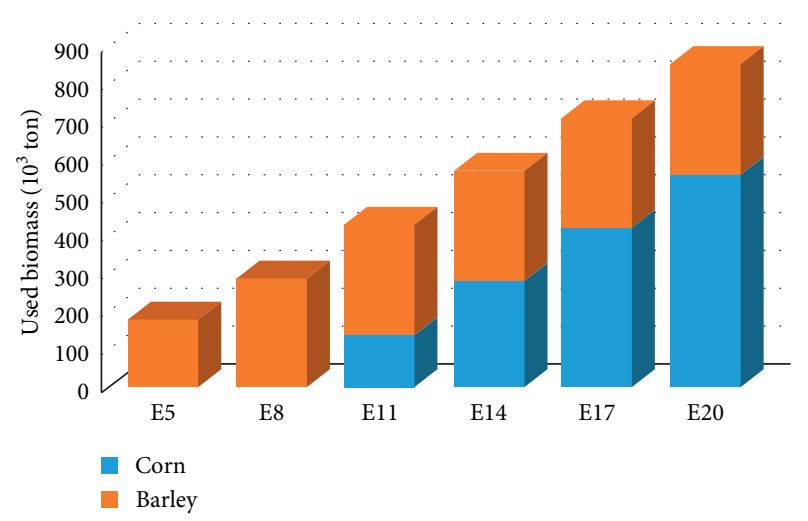

FIGURE 7: Used biomass for scenario LA1. 


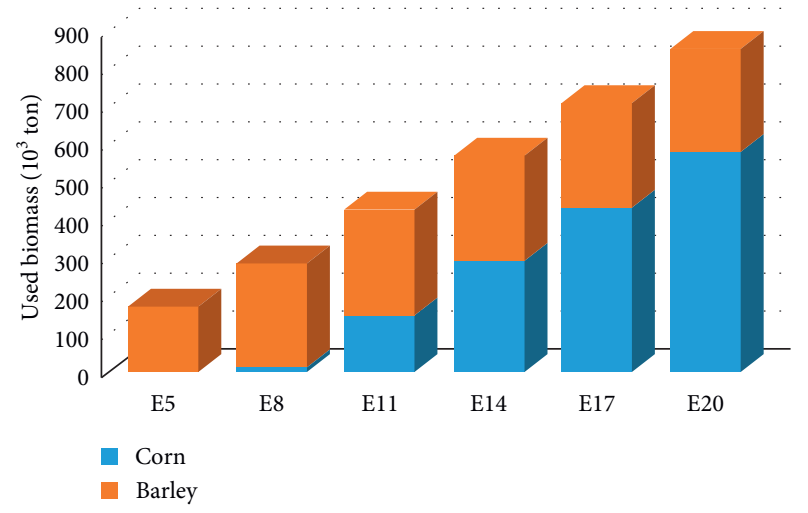

FIgURE 8: Used biomass for scenario LA2.

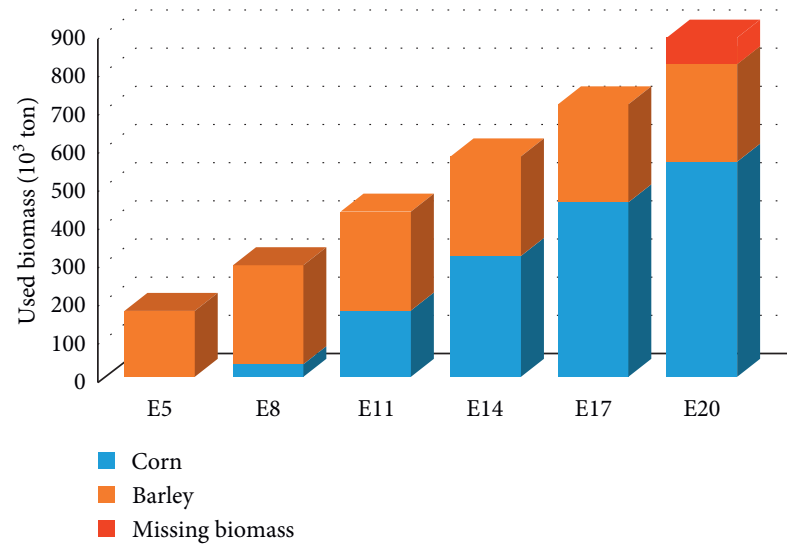

FIgURE 9: Used biomass for scenario LA3.

TABle 4: Percentage of annual gasoline demand that can be met with bioethanol.

\begin{tabular}{lccccc}
\hline \multirow{2}{*}{ Decision variables of the Bio-Eth SC } & \multicolumn{3}{c}{ Percentage of gasoline demand satisfied with bioethanol } \\
& $5 \%$ & $8 \%$ & $11 \%$ & $14 \%$ & $17 \%$ \\
\hline Annual volume of bioethanol production (MLPY) & 49.40 & 79.04 & 108.68 & 138.32 & 167.96 \\
Number of storage centers with capacity 110,000 t & 1 & 1 & 1 & 1 & 1 \\
Number of storage centers with capacity 300,600 t & 0 & 0 & 0 & 0 & 0 \\
Number of biorefineries with capacity 190 MLPY & 1 & 1 & 1 & 1 & 1 \\
Number of biorefineries with capacity 380 MLPY & 0 & 0 & 0 & 0 & 0 \\
Number of mixing plants with capacity 370 MLPY & 0 & 0 & 0 & 0 & 0 \\
Number of mixing plants with capacity 555 MLPY & 1 & 1 & 1 & 1 & 0 \\
\hline
\end{tabular}

of biomass from the harvest sites and bioethanol production processes that generate a higher yield per unit of processed biomass $(t)$.

The design of the entire SC and its operational planning is always one of the most critical challenges that make the commercialization of cellulosic biofuels possible. The strategic and operational decisions that have to do with storage facilities, biorefinery, mixing plants, biomass management, transportation, and distribution are essential for the success of the biofuels industry. Therefore, quantitative models are necessary, since they help in the decision-making of investors, government, and social agencies to understand the impact of the SC on the generation of biofuels.

\section{Conclusions and Future Research}

In this study, a decision model based on optimization is presented using mixed-integer mathematical programming (MILP) for the design of the bioethanol supply chain (BioEth SC), which includes four stages for the production of mixed fuel with bioethanol. The proposed optimization model minimizes the total cost required to build and operate the Bio-Eth SC and identifies the main decision variables, such as the types and quantities of the biomass used, quantities, and locations of the installed facilities, biomass flows, bioethanol, and mixed liquid fuel. Then we carried out the case study of the design problem of a Bio-Eth SC in the region of Tulancingo, Hidalgo, in Mexico (case study), using 


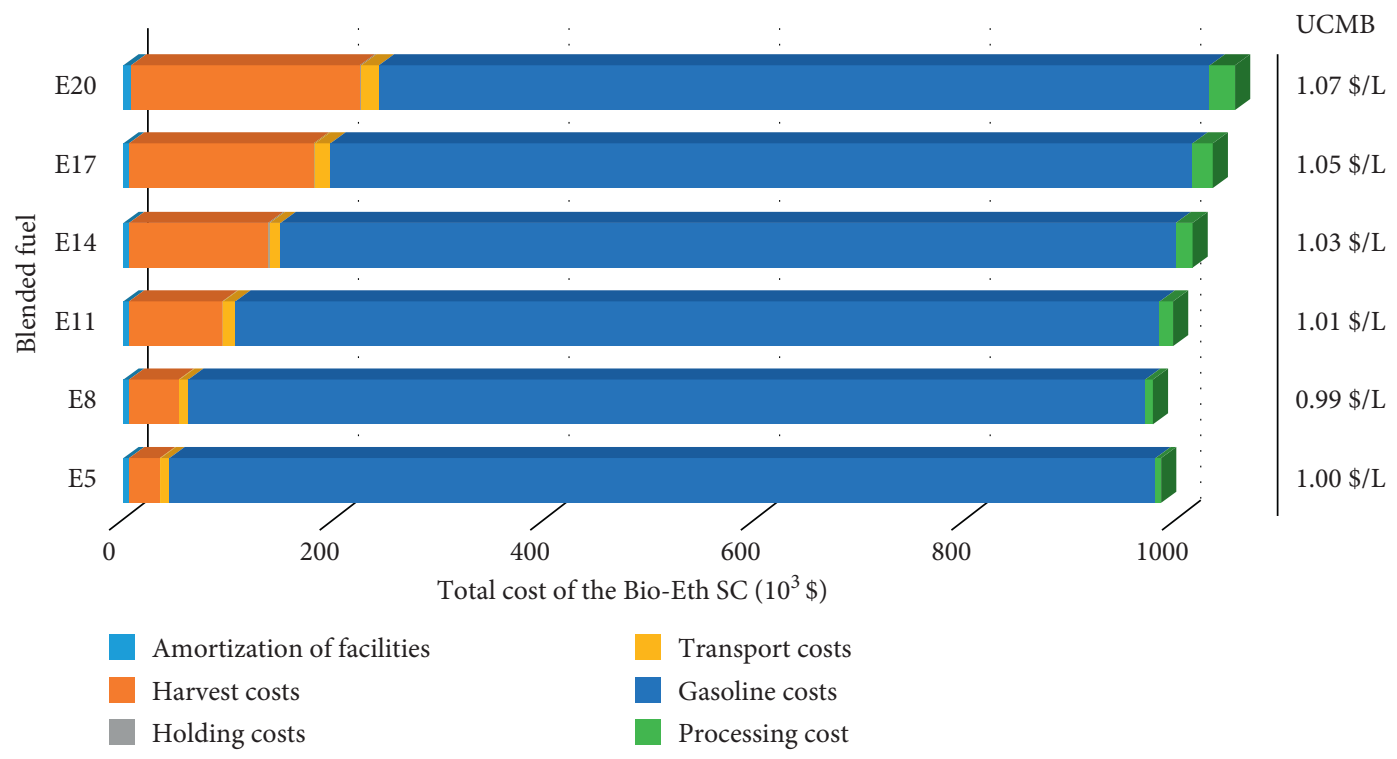

Figure 10: The cost breakdown of the Bio-Eth SC for scenario LA1.

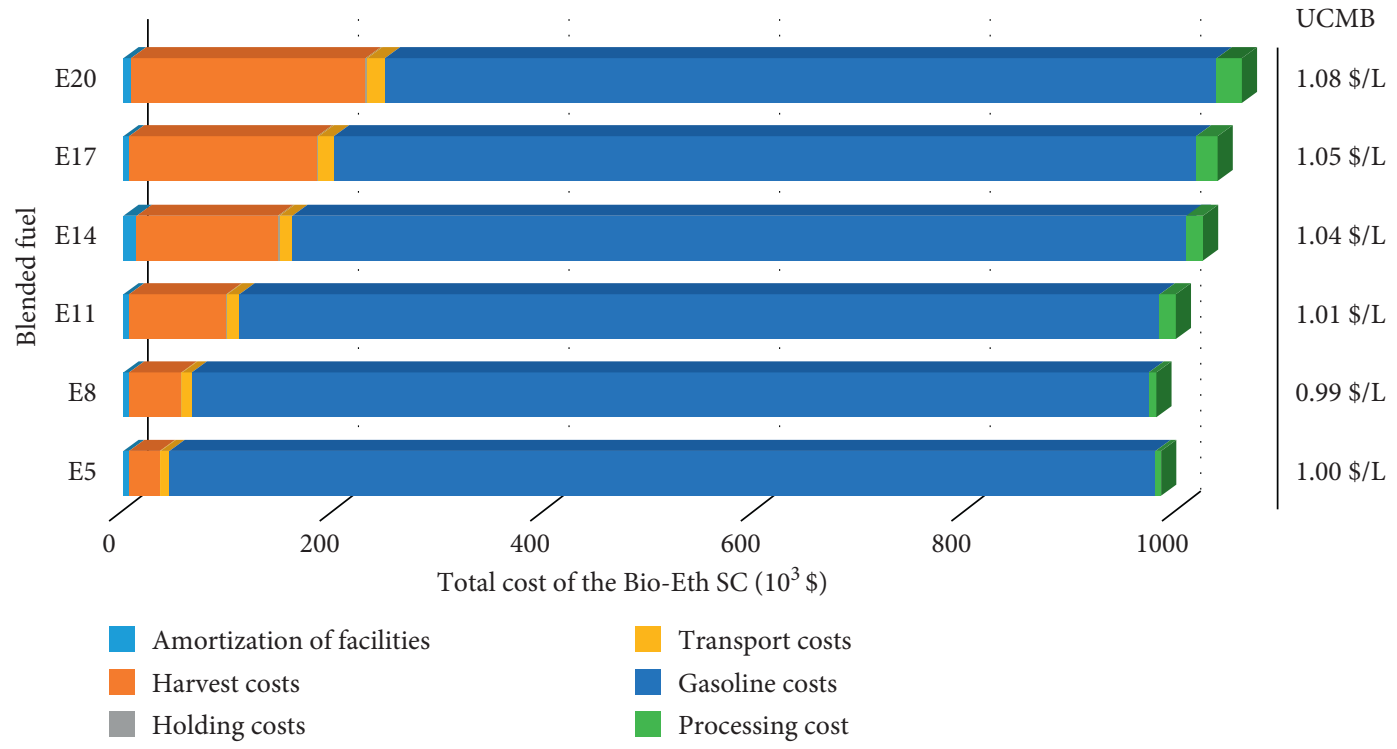

Figure 11: The cost breakdown of the Bio-Eth SC for scenario LA2.

three scenarios (LA1 100\% land availability, LA2 land availability 95\%, and LA3 90\% land availability) and six different mixing policies E5 (5\% ethanol and 95\% gasoline), E8 (8\% ethanol and 92\% gasoline), E11 (11\% ethanol and $89 \%$ gasoline), E14 (ethanol $14 \%$ and $86 \%$ gasoline), E17 (17\% ethanol and 83\% gasoline), and E20 (20\% ethanol and $80 \%$ gasoline).

The main findings of the case study are as follows:

(i) In the E8 low ethanol blending policy in scenario LA1, the mixing of liquid fuels is produced with the lowest total cost of Bio-Eth SC at the cost of \$ 0.99 per litre. On the other hand, in the E20 high-mix ethanol policy, in scenarios LA1 and LA2, Bio-Eth SC must work with two biorefineries to meet demand, which implies the highest cost per litre of mixed fuel (1.07 \$/L). However, in the LA3 scenario, additional biomass would be required to meet the demand. Therefore, the cost per unit of mixed fuel would be $1.08 \$ / \mathrm{L}$ in addition to an additional cost not calculated in this work for being out of the scope of it.

(ii) The facilities (storage centers, biorefinery, and mixing plant) tend to be installed in regions where the biomass of agricultural barley waste is more abundant to reduce the best total cost of Bio-Eth SC.

(iii) The biomass of agricultural barley residues is preferably selected against agricultural corn residues; this is also due to better yield in the conversion process.

(iv) The main contribution to the total cost of Bio-Eth $\mathrm{SC}$ is the purchase cost of gasoline to produce the 


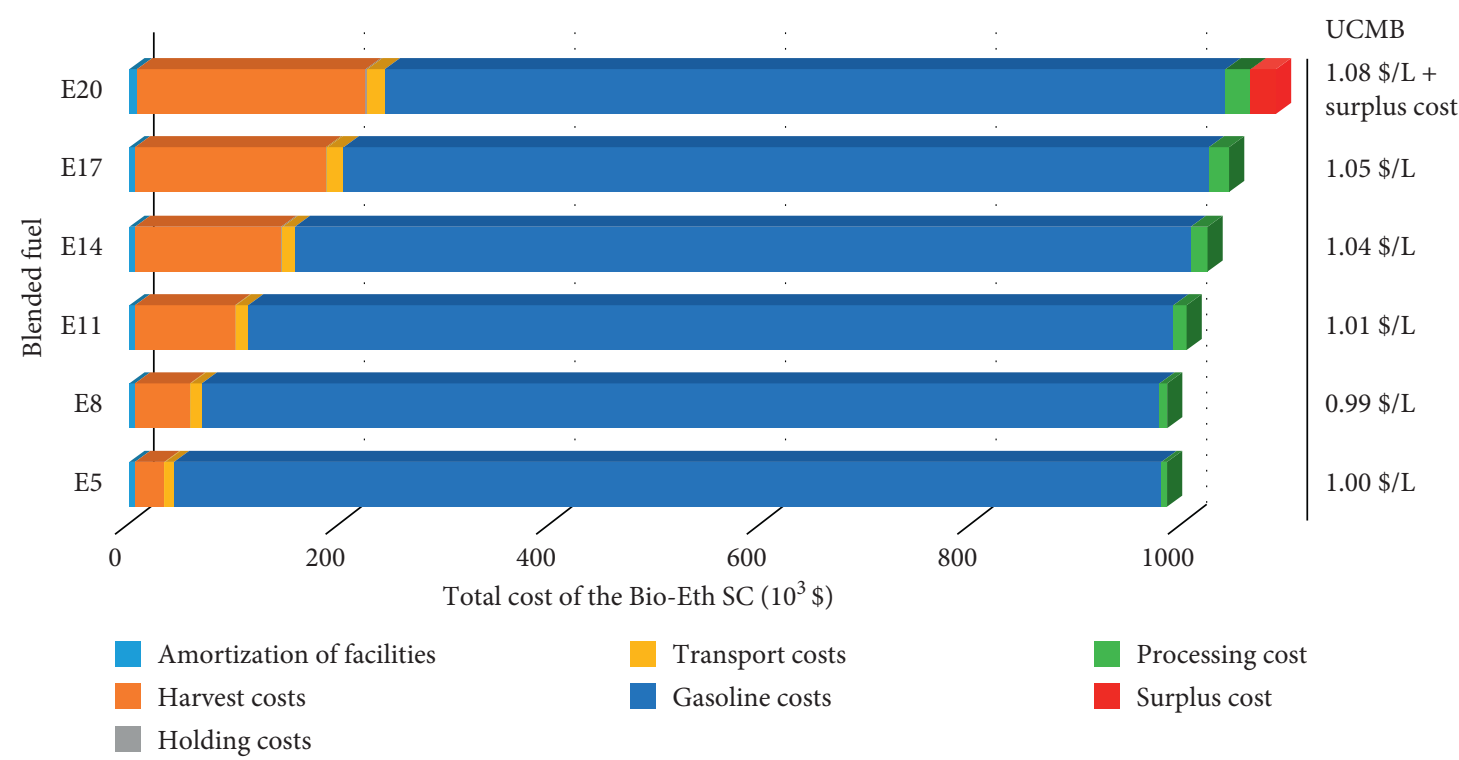

Figure 12: The cost breakdown of the Bio-Eth SC for scenario LA3.

TABLe 5: Optimal allocation of harvest sites, storage centers, biorefineries, and mixing plants.

\begin{tabular}{|c|c|c|c|c|c|}
\hline Scenario & Assigned harvest sites ${ }^{1}(i)$ & $\begin{array}{l}\text { Assigned } \\
\text { storage center } \\
(j)\end{array}$ & $\begin{array}{c}\text { Location of } \\
\text { biorefinery }(k)\end{array}$ & $\begin{array}{l}\text { Mixed plant } \\
\text { assigned }(m)\end{array}$ & $\begin{array}{l}\text { Assigned } \\
\text { customers }\end{array}$ \\
\hline LA1 & $\begin{array}{c}1,2,3,5,6,7,8,9,10,11,12,13,14,16,18,19,20,21,22, \\
23,24,26,27,28,29,31,33,34,35,36,37,38,39,40,41, \\
42,43,44,45,46,47,48,49,50,54,57,65,87,88,89,90, \\
91,92,93,94,95,96,97,98,99,100,105\end{array}$ & 2 & 1 & 2 & $1, \ldots, 224$ \\
\hline
\end{tabular}

${ }^{1}$ The names of municipalities of each location are presented in Table 1.

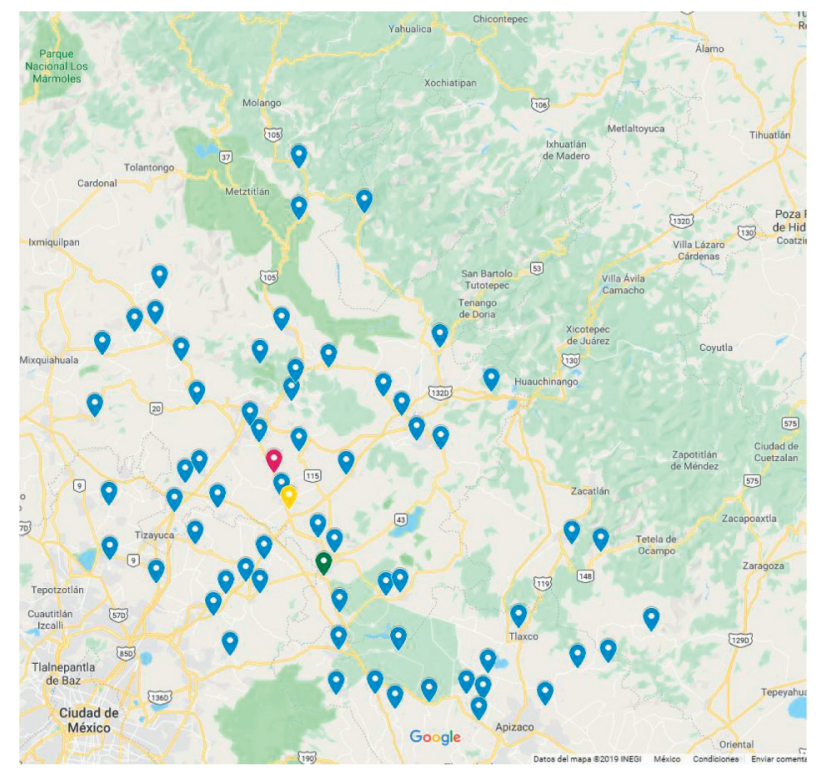

FIGURE 13: Location of harvest sites (blue), storage center (red), biorefinery (yellow), and mixing plant (green). Source: map made using Google Maps.

mixed fuel, while the cost of processing biomass for bioethanol production and biomass costs are also triggers for raising the cost of bioethanol supply. (v) We found that the unit cost of the mixture (UCMB) is not significantly sensitive to the amount of bioethanol; for example, in the LA1 scenario, only $6.7 \%$ 
TABLE 6: Breakdown of the total annual cost of the bioethanol supply chain based on corn and barley agricultural waste for mixing percentages of the E5, E8, E11, E14, E17, and E20 (\$M).

\begin{tabular}{|c|c|c|c|c|c|c|c|c|c|c|c|c|}
\hline & \multicolumn{6}{|c|}{ Cost $(\$ M)$} & \multicolumn{6}{|c|}{$\%$ concerning the total cost of the Bio-Eth SC } \\
\hline & E5 & E8 & E11 & E14 & E17 & E20 & E5 & E8 & E11 & E14 & E17 & E20 \\
\hline Opening of facilities & 5.88 & 5.88 & 5.88 & 5.88 & 5.88 & 8.32 & 0.6 & 0.6 & 0.6 & 0.6 & 0.6 & 0.8 \\
\hline Harvest cost & 29.32 & 46.90 & 89.25 & 132.25 & 175.25 & 217.54 & 3.0 & 4.8 & 8.9 & 13.0 & 16.9 & 20.5 \\
\hline Transportation costs & 8.33 & 9.63 & 10.89 & 12.45 & 14.24 & 16.53 & 0.8 & 1.0 & 1.1 & 1.2 & 1.4 & 1.6 \\
\hline Holding cost & 0.37 & 0.59 & 0.85 & 1.19 & 1.53 & 1.48 & 0.0 & 0.1 & 0.1 & 0.1 & 0.1 & 0.1 \\
\hline Fossil fuel & 938.62 & 908.98 & 879.34 & 849.70 & 820.06 & 790.42 & 95 & 92.7 & 88.1 & 83.5 & 79.0 & 74.6 \\
\hline Processing cost & 5.19 & 8.29 & 12.37 & 16.47 & 20.57 & 24.65 & 0.5 & 0.8 & 1.2 & 1.6 & 2.0 & 2.3 \\
\hline
\end{tabular}

of the total Bio-Eth SC was increased for an E20 mixture with respect to the E5 mixture. Therefore, the policy of encouraging the generation and use of alternative energy is applicable; however, the amount of energy resources derived from the productive processes of the primary sector for the production of biofuels is questionable.

(vi) Finally, the results provided by the proposed MILP model are considered adequate for the given conditions. Therefore, we can establish that the proposed approach is robust and can be used with other parameters and types of biomass.

Assumptions have been made in this study, which allows some suggestions about future work. Some assumptions that were considered by default are the locations of the facilities and the maximum number that can be opened, the maintenance costs, and the percentage of facilities used to store the product. One such opportunity for future work is the question of determining the location and number of facilities that must be opened, as well as its capabilities, such as environmental impact or sustainability analysis. The model is deterministic. Therefore, a problem to consider would be a model that incorporates uncertainty, for example, the amount of biomass and demand, to make the model more realistic. Other biomass residues and more final products could be incorporated to have a better representation of the SC.

\section{Data Availability}

The data used to support the findings of this study are included within the article in Tables 1-3 and can be obtained from the first author and corresponding author.

\section{Conflicts of Interest}

The authors declare that there are no conflicts of interest regarding the publication of this paper.

\section{Acknowledgments}

The authors acknowledge the Popular Autonomous University of the State of Puebla and the Polytechnic University of Tulancingo for their support in the present investigation as well as CONACYT for its support in the doctoral studies of Edgar León-Olivares and thank Ms. Jennifer Speier for her English redaction support.

\section{References}

[1] N. Sarkar, S. K. Ghosh, S. Bannerjee, and K. Aikat, "Bioethanol production from agricultural wastes: an overview," Renewable Energy, vol. 37, no. 1, pp. 19-27, 2012.

[2] J. Zhang, A. Osmani, I. Awudu, and V. Gonela, "An integrated optimization model for switchgrass-based bioethanol supply chain," Applied Energy, vol. 102, pp. 1205-1217, 2013.

[3] Ibero-American Agency for the Dissemination of Science and Technology, 2019, http://www.dicyt.com/noticias/ biocombustibles-a-partir-de-residuos-organicos.

[4] B. Sharma, R. G. Ingalls, C. L. Jones, and A. Khanchi, "Biomass supply chain design and analysis: basis, overview, modeling, challenges, and future," Renewable and Sustainable Energy Reviews, vol. 24, pp. 608-627, 2013.

[5] A. A. Rentizelas, A. J. Tolis, and I. P. Tatsiopoulos, "Logistics issues of biomass: the storage problem and the multi-biomass supply chain," Renewable and Sustainable Energy Reviews, vol. 13, no. 4, pp. 887-894, 2009.

[6] R. Chandra, H. Takeuchi, and T. Hasegawa, "Methane production from lignocellulosic agricultural crop wastes: a review in context to second generation of biofuel production," Renewable and Sustainable Energy Reviews, vol. 16, no. 3, pp. 1462-1476, 2012.

[7] Food and Agriculture Organization of the United Nations, Agriculture and Soil Biodiversity, Food and Agriculture Organization of the United Nations, Rome, Italy, 2019, http:// www.fao.org/agriculture/crops/thematic-sitemap/theme/spi/ soil-biodiversity/agriculture-and-soil-biodiversity/en/.

[8] R. Lal, "World crop residues production and implications of its use as a biofuel," Environment International, vol. 31, no. 4, pp. 575-584, 2005.

[9] D. Martinez, A. Feiden, R. Bariccatti, and K. de Freitas Zara, "Ethanol production from waste of cassava processing," Applied Sciences, vol. 8, no. 11, p. 2158, 2018.

[10] R. Morales, L. Agudo, and J. Espinosa, "Availability of rice and corn crop residues for the production of ethanol," Agricultural Science, vol. 24, pp. 83-92, 2016.

[11] S. M. Safieddin and A. Khademalrasoul, "An analysis of liquid-biofuel production potential from agricultural residues and animal fat (case study: Khuzestan Province)," Journal of Cleaner Production, vol. 204, pp. 819-831, 2018.

[12] A. B. Maqhuzu, K. Yoshikawa, and F. Takahashi, "Biofuels from agricultural biomass in Zimbabwe: feedstock availability and energy potential," Energy Procedia, vol. 142, pp. 111-116, 2017.

[13] C.-N. Wang, T.-T. Tsai, and Y.-F. Huang, "A model for optimizing location selection for biomass energy power plants," Processes, vol. 7, no. 6, p. 353, 2019.

[14] N. A. Sayar, O. Pinar, D. Kazan, and A. A. Sayar, "Bioethanol production from Turkish hazelnut husk process design and 
economic evaluation," Waste and Biomass Valorization, vol. 10, no. 4, pp. 909-923, 2019.

[15] S. Michailos, D. Parker, and C. Webb, "Design, sustainability analysis and multiobjective optimisation of ethanol production via syngas fermentation," Waste and Biomass Valorization, vol. 10, no. 4, pp. 865-876, 2019.

[16] A. Demirbas, "Fuels from biomass," in Biorefineries. Green Energy and Technology, Springer, London, UK, 2010.

[17] J. Laishram, K. G. Saxena, R. K. Maikhuri, and K. S. Rao, "Soil quality and soil health: a review," International Journal of Ecology and Environmental Sciences, vol. 38, pp. 19-37, 2012.

[18] A. De Meyer, D. Cattrysse, J. Rasinmäki, and J. Van Orshoven, "Methods to optimise the design and management of biomass-for-bioenergy supply chains: a review," Renewable and Sustainable Energy Reviews, vol. 31, pp. 657-670, 2014.

[19] S. D. Ekşioğlu, A. Acharya, L. E. Leightley, and S. Arora, "Analyzing the design and management of biomass-to-biorefinery supply chain," Computers \& Industrial Engineering, vol. 57, no. 4, pp. 1342-1352, 2009.

[20] H. Ghaderi, M. S. Pishvaee, and A. Moini, "Biomass supply chain network design: an optimization-oriented review and analysis," Industrial Crops and Products, vol. 94, pp. 972-1000, 2016.

[21] K. Govindan, M. Fattahi, and E. Keyvanshokooh, "Supply chain network design under uncertainty: a comprehensive review and future research directions," European Journal of Operational Research, vol. 263, no. 1, pp. 108-141, 2017.

[22] K. M. Lim and Y. Ouyang, "Biofuel supply chain network design and operations," in Book: Environmentally Responsible Supply Chains, A. Atasu, Ed., Springer, Cham, Switzerland, 2010.

[23] M. Yu, F. Cecelja, and S. A. Hosseini, "Design and optimization of biofuel supply chain network in UK," Computer Aided Chemical Engineering, vol. 32, pp. 673-678, 2013.

[24] L. Zhang and G. Hu, "Supply chain design and operational planning models for biomass to drop-in fuel production," Biomass and Bioenergy, vol. 58, pp. 238-250, 2013.

[25] H. Paulo, X. Azcue, A. P. Barbosa-Póvoa, and S. Relvas, "Supply chain optimization of residual forestry biomass for bioenergy production: the case study of Portugal," Biomass and Bioenergy, vol. 83, pp. 245-256, 2015.

[26] C.-W. Chen and Y. Fan, "Bioethanol supply chain system planning under supply and demand uncertainties," Transportation Research Part E: Logistics and Transportation Review, vol. 48, no. 1, pp. 150-164, 2012.

[27] S. Akhtari, T. Sowlati, and V. C. Griess, "Integrated strategic and tactical optimization of forest-based biomass supply chains to consider medium-term supply and demand variations,” Applied Energy, vol. 213, pp. 626-638, 2018.

[28] J. Ranisau, E. Ogbe, A. Trainor et al., "Optimization of biofuel production from corn stover under supply uncertainty in Ontario," Biofuel Research Journal, vol. 4, no. 4, pp. 721-729, 2017.

[29] A. Azadeh, H. Vafa Arani, and H. Dashti, "A stochastic programming approach towards optimization of biofuel supply chain," Energy, vol. 76, pp. 513-525, 2014.

[30] A. De Meyer, D. Cattrysse, and J. Van Orshoven, "A generic mathematical model to optimise strategic and tactical decisions in biomass-based supply chains (OPTIMASS)," European Journal of Operational Research, vol. 245, no. 1, pp. 247-264, 2015.

[31] B. Soundarya, T. L. Rex, and C. T. Maravelias, "Optimization of supply chains for production of biofuel using milp (case study: upper Peninsula of Michigan)," International Journal of
Advances in Science Engineering and Technology, vol. 4, no. 4, 2012.

[32] S. D. Ekşioğlu and C. M. Klein, "Supply chain management of biomass feedstock," in Biomass and Biofuels, J. Shibu and T. Bhaskar, Eds., pp. 77-96, CRC Press, Boca Raton, FL, USA, 2015.

[33] P. Venkat and Y. Shastri, "Conceptual design of a lignocellulosic biorefinery and its supply chain for ethanol production in India," Computers \& Chemical Engineering, vol. 121, pp. 696-721, 2019.

[34] M. Lee, S. Cho, and J. Kim, "A comprehensive model for design and analysis of bioethanol production and supply strategies from lignocellulosic biomass," Renewable Energy, vol. 112, pp. 247-259, 2017.

[35] A. T. Espinoza, M. Camargoa, P. C. Narváez, and M. A. Marchant, "Key challenges and requirements for sustainable and industrialized biorefinery supply chain design and management: a bibliographic analysis," Renewable and Sustainable Energy Reviews, vol. 69, pp. 350-359, 2017.

[36] S. Giarola, F. Bezzo, and N. Shah, "A risk management approach to the economic and environmental strategic design of ethanol supply chains," Biomass and Bioenergy, vol. 58, pp. 31-51, 2013.

[37] J. Tibaquirá, J. Huertas, S. Ospina, L. Quirama, and J. Niño, "The effect of using ethanol-gasoline blends on the mechanical, energy and environmental performance of in-use vehicles," Energies, vol. 11, no. 1, p. 221, 2018.

[38] A. Boehman, Fossil Fuel Use Is Declining-But There's Minimal Evidence That Using Ethanol Saves Money or the Environment, GreenBiz Group Inc., Oakland, CA, USA, 2019, https://www.greenbiz.com/article/fossil-fuel-use-decliningtheres-minimal-evidence-using-ethanol-saves-money-orenvironment.

[39] A. Abril and E. Navarro, "Ethanol from lignocellulosic biomass," 2018, https:/www.researchgate.net/publication/ 241216642.

[40] Government of Mexico, National Development Plan 2019-2024, Government of Mexico, Mexico City, Mexico, 2019, https://www.gob.mx/cenace/acciones-y-programas/ plan-nacional-de-desarrollo-2019-2024-195029.

[41] Government of the State of Hidalgo, State Plan of Development Hidalgo 2016-2022, Government of the State of Hidalgo, Mexico City, Mexico, 2019, http://planestataldedesarrollo. hidalgo.gob.mx/.

[42] Secretariat of Agriculture, Livestock, Rural Development, Fisheries, and Food: Agricultural Technical Agenda of the State of Hidalgo, Secretariat of Agriculture, Livestock, Rural Development, Mexico City, Mexico, 2018, https://extensionismo. sagarpa.gob.mx/web2/documentos/agenda_tecnica/F13_ Hidalgo.pdf.

[43] Secretariat of Agriculture, Livestock, Rural Development, Fisheries, and Food: Agricultural Technical Agenda of the State of Hidalgo, Secretariat of Agriculture, Livestock, Rural Development, Mexico City, Mexico, 2018, http://www.sagarpa. gob.mx/agronegocios/documents/estudios_promercado/ granos.pdf.

[44] Institute of Forestry, Agriculture and Livestock Research, Agricultural Technical Agenda of the State of Tlaxcala, Institute of Forestry, Agriculture and Livestock Research, Mexico City, Mexico, 2019, http://www.inifap.gob.mx/ Documents/inicio/Agendas_Tec/2017/Agenda\%20T\%C3\% A9cnica\%20Tlaxcala\%20OK.pdf.

[45] Institute of Forestry, Agriculture and Livestock Research, Agricultural Technical Agenda of the State of Puebla, Institute 
of Forestry, Agriculture and Livestock Research, Mexico City, Mexico, 2019, http://www.inifap.gob.mx/Documents/inicio/ Agendas_Tec/2017/Agenda\%20T\%C3\%A9cnica\%20Puebla\% 20OK.pdf.

[46] Institute of Forestry, Agriculture and Livestock Research, Agricultural Technical Agenda of the State of Veracruz, Institute of Forestry, Agriculture and Livestock Research, Mexico City, Mexico, 2019, http://www.inifap.gob.mx/ Documents/inicio/Agendas_Tec/2017/Agenda\%20T\%C3\% A9cnica\%20Veracruz\%20OK.pdf.

[47] Institute of Forestry, Agriculture and Livestock Research, Agricultural Technical Agenda of the State of Mexico, Institute of Forestry, Agriculture and Livestock Research, Mexico City, Mexico, 2019, http://www.inifap.gob.mx/Documents/inicio/ Agendas_Tec/2017/Agenda\%20T\%C3\%A9cnica\%20Edo.\% 20de\%20Mex.\%20Ok.pdf.

[48] Institute of Forestry, Agriculture and Livestock Research, Agricultural Technical Agenda of the State of Mexico, Institute of Forestry, Agriculture and Livestock Research, Mexico City, Mexico, 2019, http://www.inifap.gob.mx/Documents/ agendas_tecnologicas/15_Edomex_2015_SIN2.pdf.

[49] H. Mahmudi and P. Flynn, "Rail vs. truck transport of biomass," in Applied Biochemistry and Biotechnology, J. D. McMillan, W. S. Adney, J. R. Mielenz, and K. T. Klasson, Eds., Humana Press, Totowa, NJ, USA, 2006.

[50] Energy Information System, "National energy balance," 2019, http://sie.energia.gob.mx/movil.do?action=applyOptions.

[51] Z.-Y. Zhuang and S.-C. Chang, "Deciding product mix based on time-driven activity-based costing by mixed integer programming," Journal of Intelligent Manufacturing, vol. 28, no. 4, pp. 959-974, 2017.

[52] M. Sharifzadeh, M. C. Garcia, and N. Shah, "Supply chain network design and operation: systematic decision-making for centralized, distributed, and mobile biofuel production using mixed integer linear programming (MILP) under uncertainty," Biomass and Bioenergy, vol. 81, pp. 401-414, 2015.

[53] N. Shabani and T. Sowlati, "A mixed integer non-linear programming model for tactical value chain optimization of a wood biomass power plant," Applied Energy, vol. 104, pp. 353-361, 2013.

[54] Secretariat of Agriculture, Livestock, Rural Development, Fisheries, and Food: Agricultural Production Statistics in 2013, Secretariat of Agriculture, Livestock, Rural Development, Mexico City, Mexico, 2017, http://www.sagarpa.gob.mx/ quienesomos/datosabiertos/siap/Paginas/estadistica.aspx.

[55] K. Castillo, H. Minor, and E. Webb, "Quantifying the impact of feedstock quality on the design of bioenergy supply chain networks," Energies, vol. 9, p. 203, 2016.

[56] Secretariat of Environment and Natural Resources of Mexico, 2017, http://sinat.semarnat.gob.mx/dgiraDocs/documentos/ qroo/estudios/2004/23QR2004XD008.pdf.

[57] World Bank, Gasoline Price for the User, World Bank, Washington, DC, USA, 2018, https://datos.bancomundial. org/indicador/EP.PMP.SGAS.CD? end $=2016 \&$ locations $=$ MX\&start $=2005$.

[58] S. Heinek, S. Polanz, M. B. Huber et al., "Degradation of biomass during the storage of woodchips," in Proceedings of the 21st European Biomass Conference, Kopenhagen, Denmark, 2019.

[59] National Bank of Mexico, Exchange Rate Market, National Bank of Mexico, Mexico City, Mexico, 2019, http://www. anterior.banxico.org.mx/portal-mercado-cambiario/.
[60] Energy Regulatory Commission, Gasoline and Diesel Prices Reported by Permit Holders, Energy Regulatory Commission, Mexico City, Mexico, 2019, https://www.gob.mx/cre.

[61] Institute of Forestry, Agriculture and Livestock Research, Agricultural Technical Agenda of Mexico, Institute of Forestry, Agriculture and Livestock Research, Mexico City, Mexico, 2018, http://www.redalyc.org/pdf/608/60829101.pdf.

[62] Idaho National Laboratory, Bioenergy: Feedstock Supply System Design and Economics for Conversion of Lignocellulosic Biomass to Hydrocarbon Fuels, Idaho National Laboratory, Idaho Falls, ID, USA, 2018, http://www.inl.gov. 